Document downloaded from:

http://hdl.handle.net/10251/161696

This paper must be cited as:

Torres-Carrillo, S.; Siller, HR.; Vila, C.; López, C.; Rodríguez, CA. (2020). Environmental analysis of selective laser melting in the manufacturing of aeronautical turbine blades. Journal of Cleaner Production. 246:1-14. https://doi.org/10.1016/j.jclepro.2019.119068

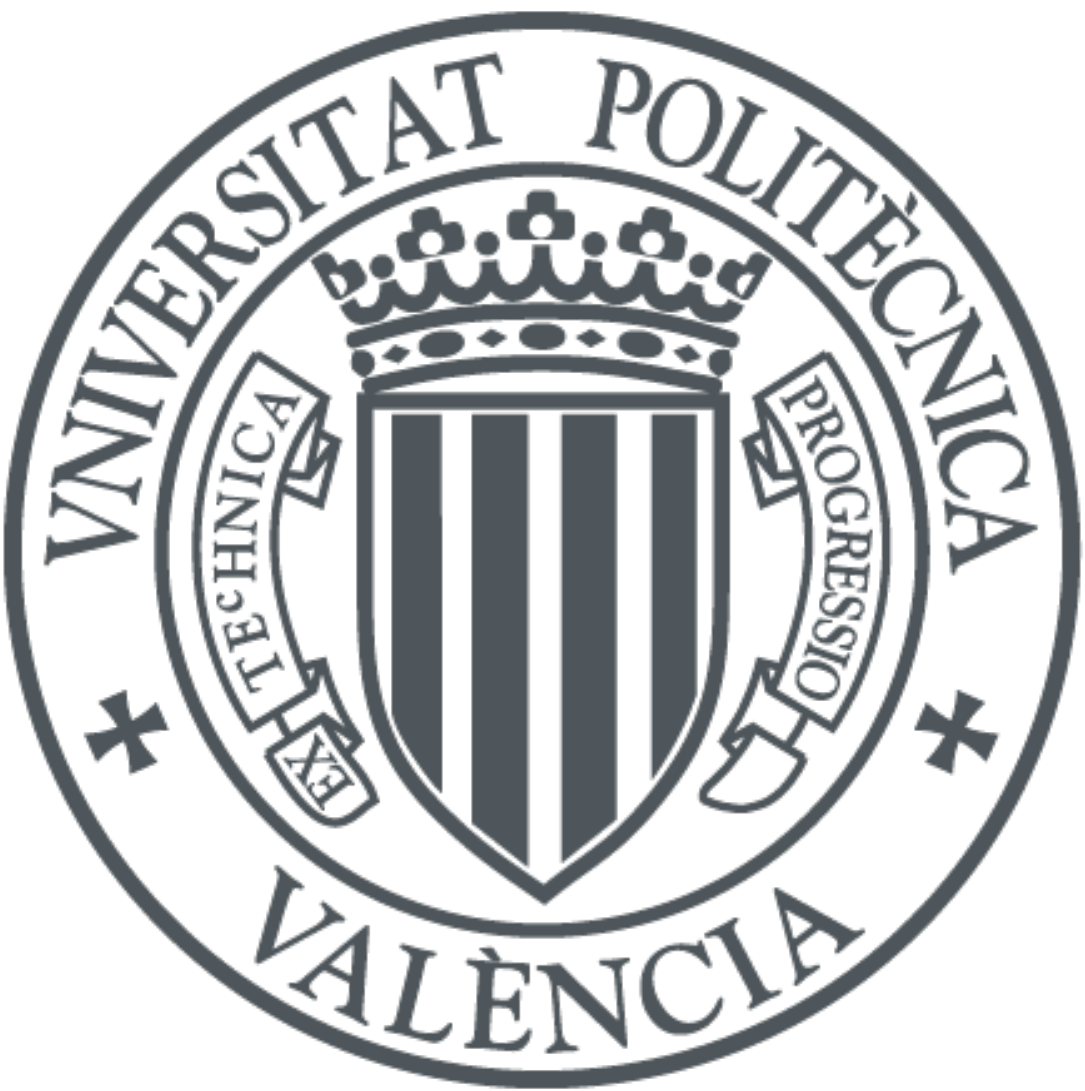

The final publication is available at

https://doi.org/10.1016/j.jclepro.2019.119068

Copyright Elsevier

Additional Information 
1

2

3

Total words: 8,813

\title{
Environmental Analysis of Selective Laser Melting in the Manufacturing of Aeronautical Turbine Blades
}

\begin{abstract}
The exponential growth of additive manufacturing technologies is not only improving production processes to achieve functional requirements for products, but it could also help to minimize environmental impacts. In order to align a green product lifecycle management vision, companies need to implement emerging technologies and define a set of metrics that measure the benefits of the change. Each product requires a particular and optimized manufacturing process plan, and each production phase must achieve a significant reduction of critical metrics for the whole Life Cycle Assessment (LCA).

This paper provides a comprehensive and comparative LCA of two manufacturing process plans for the case study of an aircraft engine turbine blade. The first process consists of a combination of Investment Casting and Precision Machining and the second consists in the replacement of Investment casting by Selective Laser Melting as an emergent process for near net shape fabrication. The collected data for the comparison includes Global Warming Potential (GWP), Acidification Potential (AP), Ozone layer Depletion Potential (ODP), Human Toxicity Potential (HTP), and Human Toxicity (HT) with cancer and non-cancer effects.

The relative analysis shows that, for the critical indicators, an apparent improvement in $\mathrm{CO}_{2}$ emissions reduction is achieved as well as in the other hazardous emissions. The results showed that the whole lifecycle of Conventional Manufacturing corresponds to 7.32 tons of $\mathrm{CO}_{2}$, while, the emission of the Additive Manufacturing is 7.02 tons of $\mathrm{CO}_{2}$. The results analysis can be used for decision-making, and it can help for facing future comparative works to explore cleaner manufacturing technologies.
\end{abstract}

Keywords: Additive Manufacturing, Life Cycle Assessment, Selective Laser Melting, Aerospace Manufacturing, Environmental Impact. 


\section{Introduction}

The aerospace sector is constantly adapting and innovating emergent manufacturing processes, towards the creation of new aircraft designs that must accomplish strict weight reduction and regulatory safety requirements. The environmental impact of the assimilation of new processing technologies is always a concern, due to the consumption of energy and the waste generation not considered before of the disruption of this kind of processes. Thus, Life Cycle Assessment in this new scenario becomes more relevant to fully understand the impact that must be addressed before the generalized use of novel fabrication methods. The environmental burdens associated with a new aeronautic product should be evaluated during all the phases and stages of its lifetime, from the material extraction until its final disposal, including the production and manufacturing, the distribution and the use of the product as well as its maintenance. In the particular case of aircraft design and manufacturing, there are different product subsystems with a specific design and functional requirements, for example, the fuselage, the wings, the stabilizers and the engine. In the particular case of this last, one may find many different parts with high mechanical performance requirements that must be designed and manufactured with tight mechanical tolerances.

In order to meet strict product requirements and at the same time higher levels of productivity and performance, advanced manufacturing processes and materials are continuously replacing and complementing conventional manufacturing technologies. Once Rapid Prototyping (RP) technologies have reached a maturity state, the emerging technologies in Additive Manufacturing (AM), especially Selective Laser Melting (SLM), have the potential to drive down cost and weight of an aircraft, by achieving acceptable levels in geometric accuracy and leading appropriate mechanical properties, while possibly reducing the environmental impact of the manufacturing cycle as well.

The use of AM offers a possibility to reduce downtime in supply chains of spare part and to reduce part inventory more effectively than CNC machining (Nyamekye et al., 2015). Additionally, AM is an innovative way to produce freeform and complex shaped parts that can be ready in hours instead of weeks. Several studies show that AM is an exponential technology and will have a boom by the year 2050, in fact, some aerospace manufacturers are already implementing it to create jigs and fixtures. Those processes are often described as "clean" processes because they only use the exact amount of material to build functional parts limiting scarps production (Le Bourhis et al., 2014). In another example of reducing waste in the 
manufacturing process, Three-dimensional printing does not require adjuvants as coolants, lubricants or other partly environmentally harmful substances (Gebler et al., 2014).

The work presented here is intended to contribute to the environmental Life Cycle Assessment for additively manufactured aeronautic components. The environmental indicators included in the framework are related to the impacts emissions of energy, materials and chemical lubricants. The study is focused on the Global Warming Potential (GWP) caused by energy consumption. The main directly related indicator with GWP is the carbon footprint, that measures all the carbon dioxide $\left(\mathrm{CO}_{2}\right)$ thrown into to the atmosphere during the manufacturing process, and to calculate the $\mathrm{CO}_{2}$ is necessary to analyze all energy consumption along the process. In order to focus the work on a specific component, the research has developed the environmental impact analysis of a turbine blade production. The case of study is applied in a manufacturing facility dedicated to produce several aeronautic components by using a variety of technologies. The study compares the present manufacturing technologies against an Additive Manufacturing technology which is Selective Laser Melting.

Additive Manufacturing Technologies have the probability to optimize the functional components in terms of weight, material costs, production time and scrap, leading to a possible lower environmental impact with an economic balance. As it is illustrated in Fig. 1(a), a commercial aircraft uses only 19\% of the weight for Payload (the load available as passengers, baggage, and freight), which is what generates profits. The actual situation confirms, as illustrated in Fig. 1(b) that the cost of the raw material is the main investment since some of the traction and power components are made by nickel-based superalloys castings and a vast variety of expensive materials.
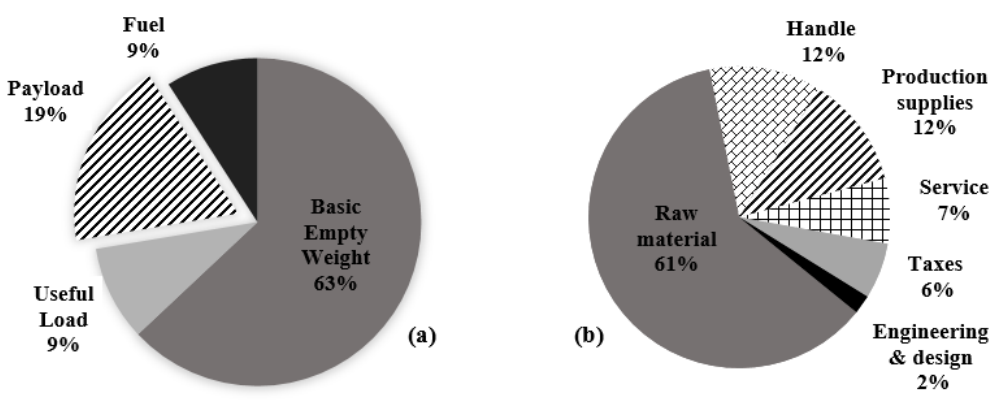

Fig. 1 Aircraft distribution of (a) weight used, and (b) cost production. 
Therefore, any decrease in the material cost and weight reduction leads to value optimization, which encourages companies to look for lighter and stronger materials. Furthermore, regarding production issues, we could find some bottlenecks when the preformed parts are no longer available from the suppliers or are discontinued in the market what makes necessary to have an agile preformed component manufacturing system. Finally, the analysis of sustainability is tied to engineering industries; this work goes beyond previous research to develop a decision-support to investment in new technology for an integrated economicalsustainability assessment where environmental impacts are considered.

\section{Literature Review}

There are available works in the literature that perform comparative Life Cycle Assessment on Additive Manufacturing technologies and the processes that are traditionally adopted for the manufacturing of aerospace/aeronautic mechanical parts, named here Conventional Manufacturing (CM). The heterogeneity of the terminology of the processes that use focused energy for melting metallic powder leads to the adoption of a common names for all of these processes: Powder Bed Fusion (PBF) and Direct Energy Deposition (DED). Under PBF classification several processes are included, such Selective Laser Melting (SLM), Electron Beam Melting (EBM), Direct Metal Laser Sintering (DMLS), and Selective Laser Sintering (SLS). Under DED classification several processes are included like Laser Engineered Net Shaping (LENS), Direct Metal Deposition (DMD), Direct Laser Additive Manufacturing (DLAM) and others.

The Table 1 contains a condensed chronological comparison of the most representative literature in PBF studies, to present the expected contribution and to set the framework of the current analysis and future investigations. (Baumers et al., 2011, 2010) dedicated their research work in the assessment of energy consumption of different PBF technologies with the use of standardized parts and batch size. The outcome of their project is a starting point of the evaluation of the process in spite of the variety of machine power, sizes and methods to deposit and melt powder layers. (Huang et al., 2016) have demonstrated the potential of saving weight, energy and greenhouses gas emissions in an aircraft component with the use Selective Laser Melting and other AM techniques. They compared mass reduction and energy consumption, and they addressed that producing AM components may use as little as $33 \%$ to $50 \%$ of the energy to produce the components with conventional techniques. (Paris et al., 2016) developed a comparison between AM and 
milling of a turbine impeller and showed the potential of AM in specific cases of parts requiring large material removal. The article has exhibited less impact in global warming and acidification with Electron Beam Melting against milling in titanium alloys and concluded that depending on shape complexity and material to be removed the processes are environmentally competitive. The work of (Kellens et al., 2017) synthetizes their previous works in the topic in which they made a LCA of PBF processes taken into account average power and other resources consumption, concluding that there is a lack of inventory data of direct and indirect process emissions and feedstock production to have reliable assessments. They addressed that the influence of weight reduction in additively manufactured components is the most important factor when adopting AM processes in automotive and aerospace applications.

Recently, (Faludi et al., 2017) elaborated a LCA of PBF processes in different machine configurations, in which they detected the dominancy of electricity impacts for nearly all the scenarios in their LCA. They used as inputs several auxiliary operations like sieving, cooling and part separation by Electro Discharge Machining (EDM), and also additional inventory items like consumables, transportation and disposal. They showed interesting evidences regarding the proportion of each data categories and calculated accurate LCA impacts with the aid of ReCiPe Europe Midpoint method metrics.

Table 1

A literature review of LCA and its comparison between AM and CNC manufacturing.

\begin{tabular}{|c|c|c|c|c|}
\hline Authors & $\begin{array}{l}\text { AM } \\
\text { Tech }\end{array}$ & Material & $\begin{array}{c}\text { Comparison to } \mathrm{CM} \\
\text { process }\end{array}$ & $\begin{array}{c}\text { Measurement indicators } \\
\text { or methods }\end{array}$ \\
\hline (Ingarao et al., 2018) & SLM & Aluminum alloys & Turning, forming & $\begin{array}{l}\text { ReCiPe characterization } \\
\text { method (Ecopoints) }\end{array}$ \\
\hline (Priarone and Ingarao, 2017) & SLS & $\begin{array}{l}\text { Titanium alloys and } \\
\text { stainless steel }\end{array}$ & Milling & $\begin{array}{l}\text { Energy demand and } \mathrm{CO}_{2} \\
\text { emissions }\end{array}$ \\
\hline (Faludi et al., 2017) & SLM & Aluminum alloys & Milling & $\begin{array}{l}\text { ReCiPe characterization } \\
\text { method (Ecopoints) }\end{array}$ \\
\hline (Kellens et al., 2017) & $\begin{array}{l}\text { SLM } \\
\text { SLS }\end{array}$ & Stainless steel & No & $\begin{array}{l}\text { Powder, gases \& specific } \\
\text { energy consumption }\end{array}$ \\
\hline (Paris et al., 2016) & $\begin{array}{l}\text { SLS } \\
\text { EBM }\end{array}$ & Titanium alloy & Milling & $\begin{array}{lr}\text { CML 2 Baseline } 2000 \text { and } \\
\text { Cumulative } & \text { Exergy } \\
\text { Demand (CExD) } & \\
\end{array}$ \\
\hline (Huang et al., 2016) & $\begin{array}{l}\text { SLM } \\
\text { EBM } \\
\text { DMLS }\end{array}$ & $\begin{array}{l}\text { Aluminum, } \\
\text { Titanium, and } \\
\text { Nickel alloys }\end{array}$ & $\begin{array}{l}\text { casting, } \\
\text { machining, } \\
\text { finishing }\end{array}$ & $\begin{array}{l}\text { Primary energy use } \\
\text { reductions and greenhouse } \\
\text { gas emissions }\end{array}$ \\
\hline (Baumers et al., 2011, 2010) & $\begin{array}{l}\text { SLM } \\
\text { EBM } \\
\text { DMLS } \\
\end{array}$ & $\begin{array}{l}\text { Stainless steel 316L } \\
\text { \& Ti6Al4V. }\end{array}$ & No & $\begin{array}{lr}\begin{array}{l}\text { Specific } \\
\text { consumption and } \\
\text { productivity }\end{array} & \text { build } \\
\end{array}$ \\
\hline
\end{tabular}


Finally, Ingarao and colleagues investigated several manufacturing routes for modeling $\mathrm{CO}_{2}$ emissions, in different life cycle stages while varying the productive scenarios. In their first work (Priarone and Ingarao, 2017) the processes used for the comparison were SLM, EBM, machining, and the materials used were titanium and stainless steel alloys. They developed a methodology to select the most environmentally friendly process if the ratio of the mass of each process scrap to the mass of the final component is known or can be hypothesized. In their second work (Ingarao et al., 2018), they used aluminum alloys manufacturing alternatives to compare turning, forming and SLM performances from environmental point of view. They found that, in spite of the less material used in SLM, the process is not competitive with the other processes, mainly as effect of the high power demanded by the laser while melting aluminum powder layers, due to high reflectivity and thermal conductivity of the material.

The Table 2 presents works related with the other classification of metal AM processes, Direct Energy Deposition (DED), in which they used similar strategies for comparing the environmental impact of AM processes and conventional manufacturing processes. The work of (Morrow et al., 2007) is one of the precursors in the field, in which they compare Direct Metal Deposition (DMD) with machining in mold and die manufacturing. They found that the DMD process is competitive when the process is used in re manufacturing operations after a first machining process. The study gives insights of the advantage of AM over ingot casting for particular combinations of processes, which may be due to the intensive use of energy during the consolidation of the stock material. The research of (Wilson et al., 2014) is also concluding that there is an environmental advantage in the use of AM techniques in the remanufacturing of a turbine blade, in comparison with the full manufacturing process based on investment casting. Serres et al. have demonstrated in a case study, that a structural airplane component can be manufactured by an AM process (DLAM) in which manufacturing-related energy demands and $\mathrm{CO}_{2}$ emissions can be lowered by up to $70 \%$ in comparison to monolithic titanium alloys machining (Serres et al., 2011). Finally, (Le Bourhis et al., 2014) delivered a predictive model for environmental assessment, in which they established some rules and guidelines for the decision making for the manufacturing of a part via Direct Laser Additive Manufacturing (DLAM) and its corresponding pre and post processes.

After the review presented here, is evident that there are several areas of opportunity to explore and that there is still a high level of uncertainty and contradictions in LCA of AM process, in regard to their real 
inclusion in the manufacturing routes of precision components. The research presented here is intended thus to contribute with another case study, that can lead to the exploration of all aspects that may affect the environmental performance of additively manufactured parts prior to their full introduction in the industry. The originality of the work in comparison with previous research, relies in the exposition of all the aspects that may influence the decision making of AM adoption for replacing or complementing the investment casting in the manufacturing of Inconel turbine blades, by a comprehensive LCA of the process chain that needs to be performed in a real production scenario.

Table 2

Literature review focus on works related with the other classification of metal AM processes.

\begin{tabular}{lllll}
\multicolumn{1}{c}{ Authors } & AM Tech & \multicolumn{1}{c}{ Material } & $\begin{array}{c}\text { Comparison to CM } \\
\text { process }\end{array}$ & $\begin{array}{c}\text { Measurement indicators } \\
\text { or methods }\end{array}$ \\
\hline (Wilson et al., 2014) & LENS & Nickel alloys & Welding & Energy consumption \\
\hline (Le Bourhis et al., 2014) & DALM & Aluminum & No & $\begin{array}{c}\text { Energy, fluids and material } \\
\text { consumption }\end{array}$ \\
\hline (Serres et al., 2011) & DLAM & Titanium alloys & Machining & Energy consumption \\
\hline (Morrow et al., 2007) & DMD & Tool steel & CNC Milling & Energy consumption \\
\hline
\end{tabular}

\section{Research Approach}

\subsection{Case Study Analysis of the Part Manufacturing Process}

For the research work presented here, a turbine blade manufacturing process chain is analyzed. The turbine blade is the individual component of an array of curved palettes in a turbomachine for aircraft power engines. The turbine blades are responsible for extracting energy from the combustion chamber, they can divert the current flow to the transformation between kinetic energy and pressure energy and are exposed to the highest temperatures experienced by the engine. Due to this particular function, the geometry of this part is extremely complex, as it is illustrated in Fig. 2, and the materials for the part are expensive in comparison with other aeronautic alloys. The manufacturing of the turbine blade is a complex process because it is originally performed by using two main manufacturing technologies, Investment Casting and Precision Machining Manufacturing, in order to obtain the required shape and its geometrical and dimensional tolerances. This implies, in our particular scenario, the knowledge and the resources of two different suppliers with a high degree of specialization in their respective area. 

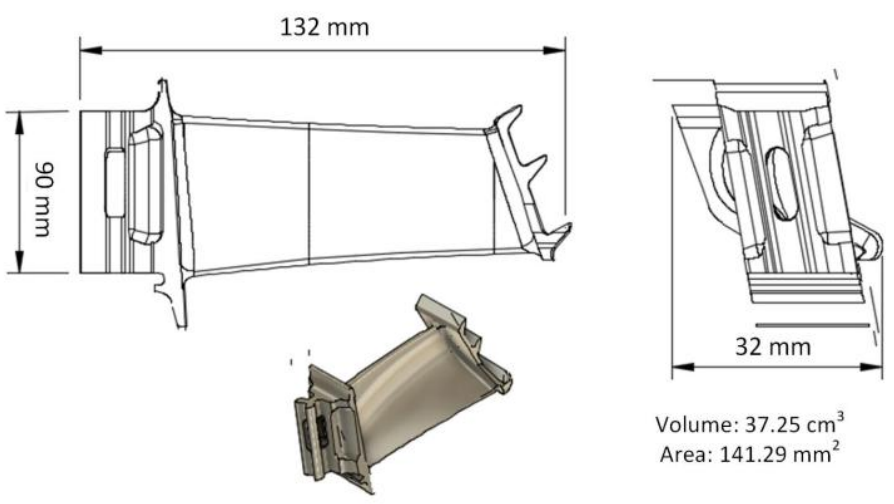

Volume: $37.25 \mathrm{~cm}^{3}$ Area: $141.29 \mathrm{~mm}^{2}$

Fig. 2 CAD Model of a turbine blade.

For the first manufacturing phase, the casting company (Supplier A) performs the investment casting process where the casting is elaborated from raw material with ceramic molds that are filled with high melting point metallic alloys by gravity, pressure, vacuum or centrifugal force techniques (Degarmo et al., 2003). Later, during the second manufacturing phase, the machining company (Supplier B), is in charge of the final stage and transforms the casted preform into a net-shaped turbine blade. The simplified described process of an aerospace turbine blade is shown in Error! Reference source not found.. In order to improve the anufacturing process of the part, from the environmental point of view while maintaining its mechanical, functional and geometrical design standards, a deep analysis of each manufacturing technology is performed to compare alternatives.

\section{Part Design $\quad$ Manufacturing Process Plan}

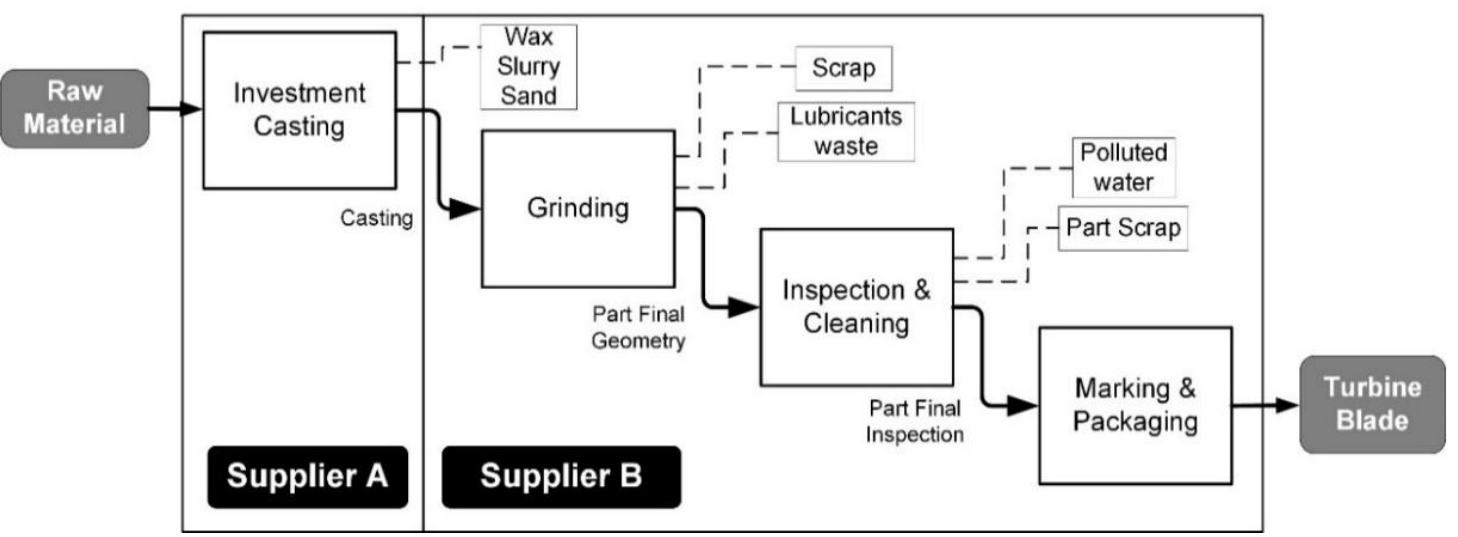

Fig. 3 Turbine blade Manufacturing process plan for aircraft engines. 


\subsection{Analysis of the manufacturing technologies}

\subsubsection{Investment Casting}

Investment Casting (IC), also known as "lost wax casting," is known for its ability to produce components of superior surface finish, dimensional accuracy and with high degrees of shape complexity. It is especially useful for making castings of complex and near-net shape geometries, where machining may not be possible or too wasteful. Traditional IC suffers the disadvantage to be an expensive process from high tooling costs for producing wax patterns (Pattnaik et al., 2012).

The IC technique studied here consists of 5 stages. The first stage is to produce wax patterns, made by injection or pouring molten wax into the master die under pressure and then the individual wax patterns are adhered to a central wax sprue, the result is a tree pattern model. In the second stage, a ceramic shell is made, the wax patterns are invested with ceramic or refractory slurry, which is then solidified to build a shell around the wax pattern tree. Currently, it takes around 24-72 hr., depending upon the size, quantity, and material of the component. After this stage, the pattern is melted, the mold is hardened and held in inverted form to drain the wax, and this last stage is known as dewaxing. Once the mold is preheated at high temperatures for the elimination of all the contaminants, which also facilitates the metal flowing into the cavity more easily, the molten metal is poured into the mold by gravity and then solidifies. At the final stage of manufacture, the shell mold is broken away from the solid part, given as result a raw part that only needs a heat treatment to obtain a casting. The stages and inputs of the investment casting process during this phase are illustrated in

\section{Fig. 4 .}

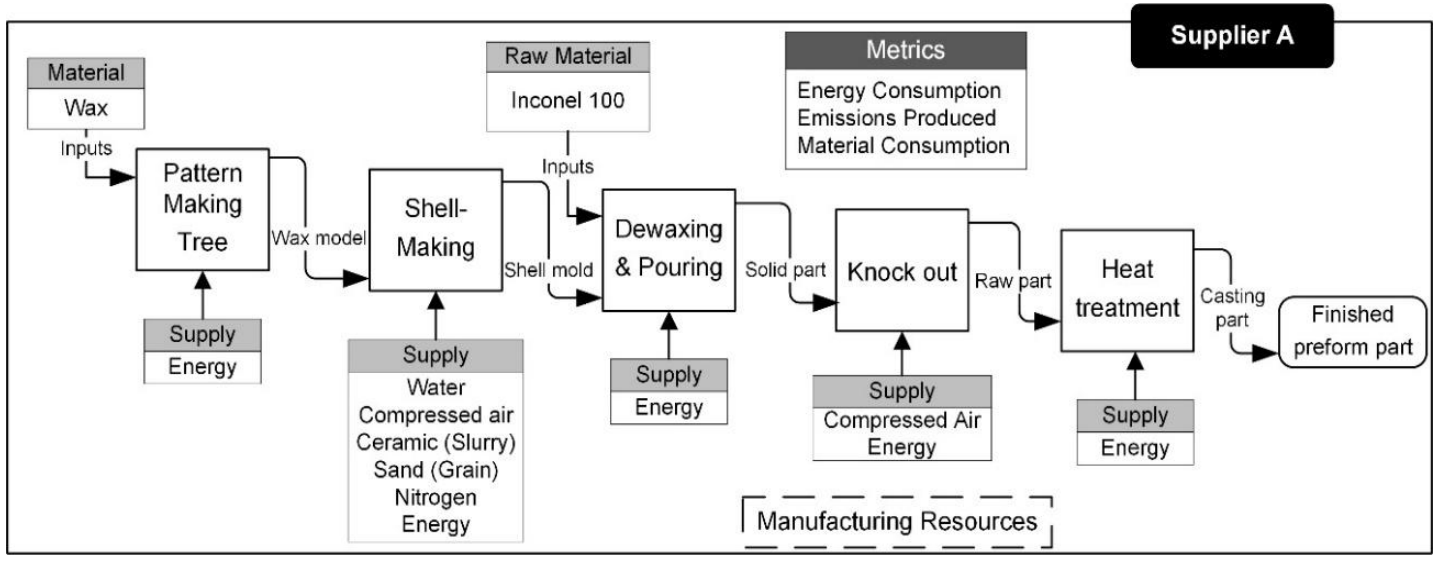

Fig. 4 Analysis of inputs in the Investment Casting process. 


\subsubsection{Precision Machining Manufacturing}

The final mechanical process in the manufacturing chain of a turbine blade is Precision Machining Manufacturing (PMM). This phase is divided into 5 stages, and the first stage is composed by a grinding

process. The process consists, basically, in 3 grinding operations that modify the shape of the casted part in order to obtain the final geometry with accurate dimension and to meet dimensional and geometrical tolerances. The first operation is to grind the main slotted geometry of the assembly area, the second operation is the tip/slot grinding of one side of the part, and the third is the grinding operation that machines the cap of the part.

After the grinding operations, the casting part goes through three stages of chemical cleaning operations in order to detect anomalies and defects (Fig. 5). The first one is a cleaning operation with nitric acid and deionized water, in which casting parts are submerged into a tank at room temperature with the chemical agents previously mentioned. In the next stage, the part is dried in a furnace for 1 hour and is taken to fluorescence testing with penetrating liquids and powders (Fluorescent Penetrant Inspection: FPI), to show possible fissures and defects that may become visible under fluorescent light. Consequently, the purpose of this FPI operations is to find any evidence of cracks that could be present in the surface checking in detriment of the surface integrity.

The following step is the shot peening operation stage. The shot peen technique is a cold deformation process that generates a uniform layer of compressive stresses in order to analyze any defect that could have the part and prevents failures due to corrosion under stress. Finally, the part is marked and packed in the last stage, and the result is a turbine blade as a finished part. 
Fig. 5 Analysis of inputs of the Precision Machining Manufacturing process.

\subsubsection{Selective Laser Melting}

As it has been introduced, Additive Manufacturing could be an alternative to some manufacturing technologies considering different approaches. There are several AM technologies for metallic alloys, based on powder bed fusion or direct energy deposition that may be applied as alternatives to compete with investment casting. However, it has been chosen a particular type of powder bed fusion, denominated Selective Laser Melting (SLM), which is one of the processes of interest in the aeronautic industry, due to its versatility, potential cost reduction and relative productivity (Read et al., 2015). In SLM, fine metallic powder layers $(25-50 \mu \mathrm{m})$ are spread out on a building platform with the aid of a roller or a recoated. The powder is selectively heated by a high-power density laser beam to its melting temperature, and its energy is calibrated in such a way that each layer of metallic powder is fully molten and joined to the molten particles of the previous layer. In order to pre-process the geometries, the procedure starts by slicing the 3D CAD file data into layers, from 20 to $75 \mu \mathrm{m}$, with $1 \mu \mathrm{m}$ increments. The system schematic of this technique is illustrated in Fig. 6. The SLM process has the ability to melt the metal material into a solid 3D-dimensional part fully, that is why the process is generally named as $3 \mathrm{D}$ metal printing., which is likely to be more competitive than conventional manufacturing when it comes to fabricating products with higher levels of complexity, customization, or a combination of both (Conner et al., 2014). 
The aerospace industry is focused in the adoption of SLM because of the possibility of manufacture lighter structures to reduce weight, which is the common goal of aircraft and spacecraft designers (Wong and Hernandez, 2012). Also, because of the possibility to reduce downtime in supply chains of spare part and reduce part inventory more efficiently than Conventional Manufacturing.

\subsection{Life Cycle Assessment Approach}

The approach of this research is to explore the benefits that may be carried out by changing from IC to SLM in a stage of the process plan of turbine blades manufacturing and exploring its implications for the whole lifecycle in sustainable metrics including the phase of precision machining. Life Cycle Assessment (LCA) is the only eco-design tool that investigates, quantifies the consumption of resources and evaluates the environmental impacts, in which results might be valuable contributions to decision-making processes. The LCA methodology used in this work is based on ISO 14044:2006 - Environmental management - Life cycle assessment - Requirements and guidelines (International Organization for Standardization, 2006).

The LCA is classified into three different measuring range; these are gate-to-gate, cradle-to-gate and cradle-to-grave (The British Standards Institution, 2011). The analysis of cradle-to-grave is the full life cycle assessment from resource extraction until final disposal phase, cradle-to-gate it is an assessment of a particular product lifecycle from resource extraction to the product manufacturing, and gate-to-gate is a partial 
LCA taking into account only one value-added process in the entire production chain, as it is illustrated in

Fig. 7.

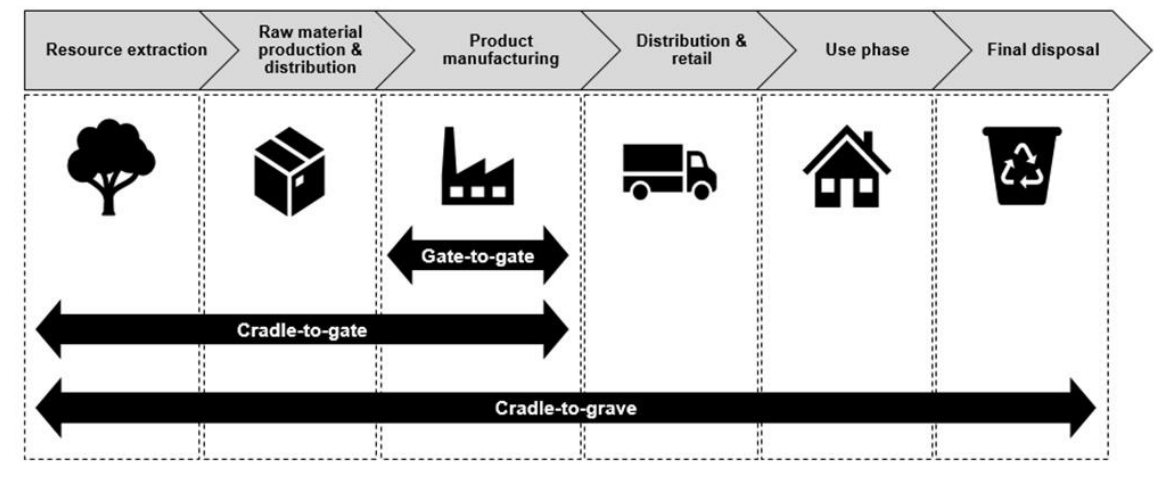

Fig. 7 Classification of the analysis to define a lifecycle.

This study will be limited to gate-to-gate analysis in the product manufacturing stage in which we will consider the inputs and outputs of the production process. Although LCA implies considering all the transformation stages of the part from cradle-to-grave, the work is going to be focused on the previously described phases. Within the manufacturing process phases and the described stages, we will consider only the technical factors related to each operation. Factors such as maintenance, human capital, transport and production of secondary materials are out of the scope of this study in order to present a technology-based comparison. Manufacturing data acquisition of SLM and PMM data gathering will be done offline on the shop floor, and IC phase metrics will be complemented with data from the previous literature.

\section{Experimental Procedure}

According to the functional requirements and mechanical properties specifications for turbine blades of an aircraft engine hot chamber, the most suitable materials for their construction are Nickel based alloys, due to their mechanical performance in high-temperature environments (Vilaro et al., 2012). In the particular case of Investment Casting the alloy taken into account for the comparison is the Nickel alloy 100 (Inconel 100). In the case of SLM manufacturing process, the material selected is the Nickel alloy 718 (Inconel 718). It is assumed that both alloys are comparable in terms of their processing and near net-shaping, due to their similar chemical composition. The conceptual comparison of alternative manufacturing processes between 
Conventional Manufacturing (Investment Casting plus Precision Machining Manufacturing) and Additive manufacturing (Selective Laser Melting plus Precision Machining Manufacturing) is represented in Fig. 8.

Although the PMM is the common process between the two-process chain to be evaluated, it might be possible that technical parameters could slightly vary in this process since the metallographic structures could be different due to the technology change and the slight material composition change. However, this difference may be neglected due to its minor impact on the general perspective of this study.

Adverse environmental impacts can be caused by emissions to air, discharges into water, generation of solid wastes and many others very difficult to measure. The number of metrics can be vast, and we must define and select the correct ones for an accurate sustainability comparative analysis. For the case study, a turbine blade of an aircraft engine, we propose to select the most critical indicators in the manufacturing period of its lifecycle, in which General Life Cycle Assessments are focused on carbon footprint.

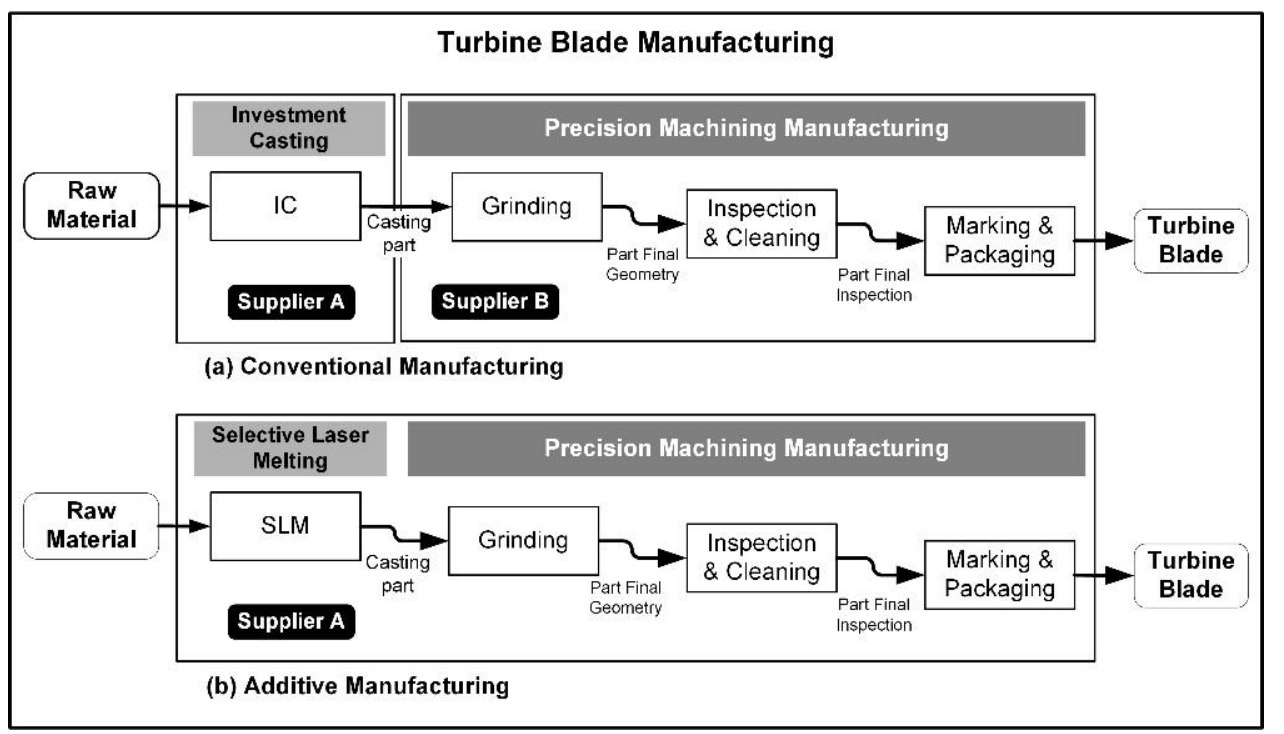

Fig. 8 Schematization of the case study to be compared, (a) CM, and (b) AM.

This indicator is released into the atmosphere, therefore is used as a generic synonym for emissions of carbon dioxide or greenhouse gas emissions expressed in kilograms of $\mathrm{CO}_{2}$ equivalents as a functional unit. The carbon footprint stands for a certain amount of gaseous emissions that are relevant to climate change and associated with human production or consumption activities (Wiedmann, 2007). In some way, the carbon footprint indicator measures the global warming, and the associated metric can be defined as Global Warming Potential (GWP). From the perspective of sustainability, there are other leading indicators (Table 3) that can 
help to have a general view, such as Acidification Potential (AP), Ozone layer Depletion Potential (ODP), Human Toxicity Potential (HTP), and Human Toxicity (HT) with cancer and non-cancer effects.

Apart from this sustainability indicators, there are many others that may be used to measure more detailed aspects of the part lifecycle by including economic and social indicators. In the case of our particular study, the energy consumption will be correlated as an economic indicator, which is going to be handled for each operation and stage. On the other hand, social indicators are out of the scope of this research. In our work scenario, the target is to perform a comparative study with two alternative manufacturing process chains that can be considered equivalents in terms of achieving the final net shape, so the results can be appropriately analyzed and interpreted. In order to evaluate each process, it is necessary a data collection that confirms the inventory analysis.

\section{Table 3}

Description of environmental impact indicators to be measured in the experimental procedure (Adapted from (Europoles GmbH \& Co.KG, n.d.)

\begin{tabular}{|c|c|}
\hline Indicator & Description \\
\hline GWP & $\begin{array}{l}\text { A measure of how much unit mass of gas contributes to global warming compared to carbon dioxide. A } \\
\text { product with a low GWP value causes only low gas emissions contributing to global warming. }\end{array}$ \\
\hline $\mathrm{AP}$ & $\begin{array}{l}\text { Refers to the effects of acidifying emissions, therefore, a measure of the environmental impacts of } \\
\text { acidification of soils and waters. The higher AP value is higher the risk of acid rain and environmental } \\
\text { damage associated with it. The reference compound for calculating is } \mathrm{SO}_{2} \text { (sulfur dioxide). }\end{array}$ \\
\hline ODP & $\begin{array}{l}\text { The indicator refers to the thinning of the stratospheric ozone layer because of anthropogenic } \\
\text { emissions. This causes a more significant fraction of solar UV-B radiation to reach the earth's surface, } \\
\text { with potentially harmful impacts on human health, animal health, terrestrial and aquatic ecosystems. }\end{array}$ \\
\hline HTP & $\begin{array}{l}\text { This impact category covers the impacts on human health of toxic substances present in the } \\
\text { environment. The health risks of exposure in the workplace are also sometimes included in LCA. These } \\
\text { latter risks are often included in a wider impact category encompassing more than exposure to toxic } \\
\text { substances. }\end{array}$ \\
\hline $\begin{array}{l}\text { HT cancer } \\
\text { effects }\end{array}$ & $\begin{array}{l}\text { Human toxicity has a potential to increase human disease per unit mass of a chemical emitted. } \\
\text { Comparative toxic unit for human (CTUh), it is the reference quantity of cancer human health effect. }\end{array}$ \\
\hline
\end{tabular}

Both processes shall be compared using the same functional units and equivalent methodological considerations, such as performance, system boundaries, data quality, allocation procedures, and decision rules on evaluating inputs and outputs and impact assessment. Any differences between measurements regarding these parameters shall be identified and reported. 


\subsection{Inventory analysis}

Inventory analysis involves data collection and calculation procedures to quantify relevant inputs and outputs of a production system. Material and liquid material and the resulting outputs such as emissions and wastes are shown in Table 4.

From the sustainability point of view, these inputs and outputs may include the use of resources, air emissions, water and ground pours and energy consumption associated with the production system (International Organization for Standardization, 2006). Input and output models have been shown to be useful for sustainability analysis; materials flow analysis and energy through industrial processes (Huang et al., 2016; Lenzen et al., 2003; Wilson et al., 2014). In this case study, the material flow analysis models must be identified and quantified for its assessment analysis.

\section{Table 4}

Inventory data to be considered for selected metrics in each manufacturing technology.

\begin{tabular}{lrr}
\hline Investment Casting & Inputs & Unit \\
\hline Metal bar Inconel 100 & 67.12 & $\mathrm{Kg}$ \\
\hline Ceramic (slurry) & 16.66 & $\mathrm{Kg}$ \\
\hline Sand (grain) & 16.66 & $\mathrm{Kg}$ \\
\hline Wax & 2.4 & $\mathrm{Kg}$ \\
\hline Electricity, production mix & 10853 & $\mathrm{kWh}$ \\
Precision Machining Manufacturing & Inputs & Unit \\
Casting Nickel alloy & 48.06 & $\mathrm{Kg}$ \\
\hline Shot Peen & 4.25 & $\mathrm{Kg}$ \\
\hline Electricity, production mix & 5168 & $\mathrm{kWh}$ \\
\hline Water (desalinated; deionized) & 6889 & $\mathrm{~L}$ \\
\hline Penetrant Liquids (ZR-10B, ZP-4B \& ZL-37) & 27.5 & $\mathrm{~L}$ \\
\hline Cooling oil (CIMTECH 320 \& 610) & 35.39 & $\mathrm{~L}$ \\
\hline Chemical lubricants (Nitric acid, OAKITE \& ECOMATE) & 345 & $\mathrm{~L}$ \\
Selective Laser Melting & $\mathrm{Inputs}$ & $\mathrm{Unit}$ \\
\hline Powder Inconel 718 & 70.51 & $\mathrm{Kg}$ \\
\hline Electricity, production mix & 10182 & $\mathrm{kWh}$ \\
\hline Water (desalinated; deionized) & 1 & $\mathrm{~L}$ \\
\hline Compressed air & 1 & $\mathrm{Nm} 3$ \\
\hline Argon & 2 & $1 / \mathrm{m}$ \\
\hline
\end{tabular}

\subsubsection{Investment Casting Sustainability Analysis}

As it has been explained in Fig. 4, the Investment Casting phase includes several discrete operations. Some operations require repetitive cycles that necessitate a considerable amount of time and energy apart from the material and wastes that shall be monitored carefully. A general vision of the sustainability analysis 
for this manufacturing process can be seen from the Fig. 9, which shows the inputs, outputs and proposed metrics for the research.

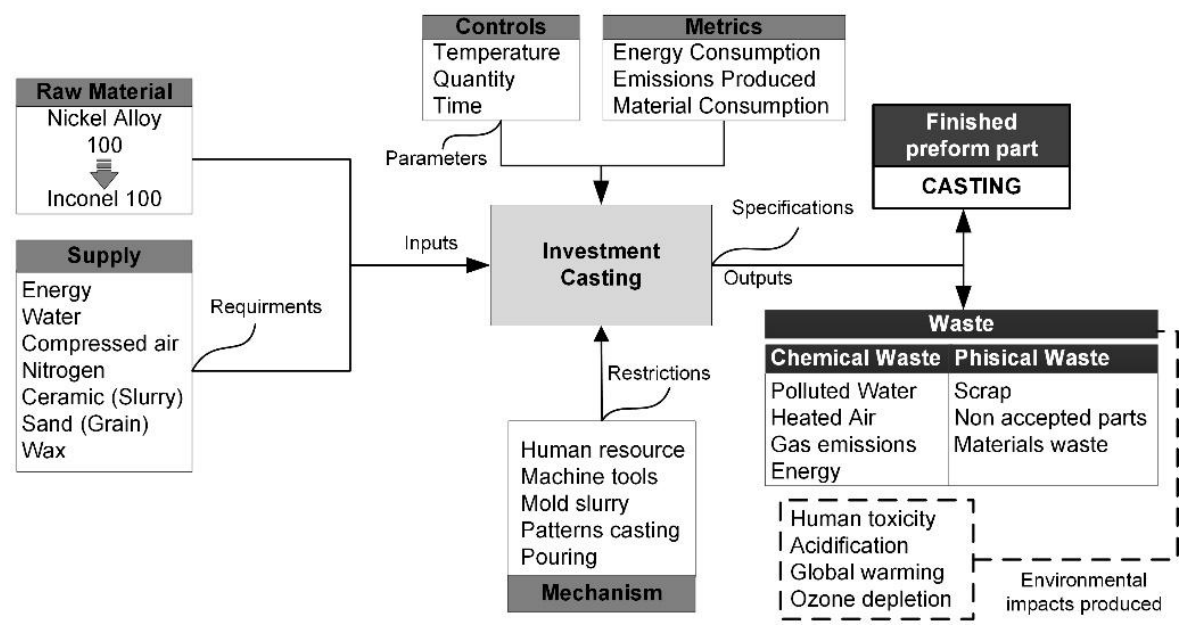

Fig. 9 Sustainability analysis of Investment Casting process.

The data obtained for Investment Casting Life Cycle Inventory (LCI) comes from literature and data mining from the process. Due to the fact that some stages are not yet equipped with a sensor, a rigorous analysis of Pattern Making, Shell Making and Knock Out stages was made from literature and similar machinery data estimation. The estimation of the molten metal in the pouring stage was obtained from a report of Energy and Environmental of metal casting industry (Margolis et al., 1999). In the same way, the data from the fabrication of raw material (metal in bar stock form) was taken from specialized literature (Wilson et al., 2014).

\subsubsection{Precision Machining Manufacturing Sustainability Analysis}

The second main phase of the first case study is the Precision Machining Manufacturing (PMM) stage. For the Grinding, heavy machinery is used due to the high requirements of forces and energy inherent in these machining operations. Here we find the most relevant impact in energy consumption measured, along with the quantities of chemical, lubricants, and fluids, which will be determined per their concentration percentage in each cleaning operation and inspection area. It is important to specify that the data of energy and fluids consumption were calculated per batch of 600 parts $(48.06 \mathrm{~kg})$ as a standard measurement. To show a general vision with all the inputs and outputs the sustainability analysis is illustrated in Fig. 10. In regard to the consumption of fluids, in the PMM stage, the fluid is CIMTECH 320 (cooling oil), compound by 
triethanolamine (30\%), neodecanoic acid (13\%), nonanoic acid (5\%) and mono isopropanol amine (5\%). During the Nitric Clean (NC), the fluids used are OAKITE (65\% of sodium hydroxide), ECOMATE (89\% of dihydrogen monoxide) and Nitric Acid.

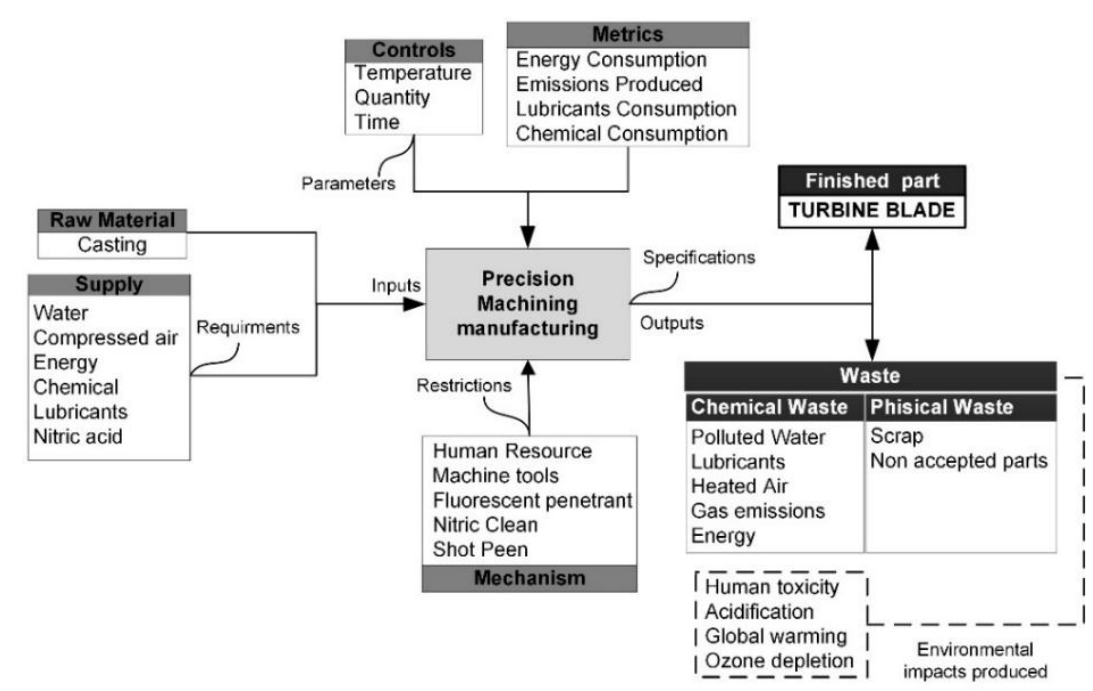

Fig. 10 Sustainability Analysis of Precision Machining Manufacturing.

Another part of the process illustrated in Fig. 10 consists of quality inspection, in which the use of Fluorescent Penetrant liquids is mandatory for detecting cracks and defects in the machined area of the blade. In penetrating impregnation, dry powder developer (pentaerythritol $60 \%$ and manganese in alloy $30 \%$ ) is used for revealing the cracks. In the Prewash area, the blades are immersed in hydrophilic emulsifier (ethoxylated 60\%), and finally, in the Emulsifier tank, fluorescent penetrant powders (isodecyl diphenyl phosphate 60\%) are used.

\subsubsection{Selective Laser Melting sustainability analysis}

For the alternative solution analysis, a similar procedure has been followed. In this process, we have slightly different inputs and outputs. First, the material is now powder Inconel 718, the calculation of powder fabrication was taken from the literature of gas atomization process for metal powder fabrication. Furthermore, the amounts of material, energy, water, and argon were own measurements taking into consideration the time and temperature of the building process. These are the main parameters to analyze for the identification of environmental indicators considering the lifecycle approach. The metric units are presented as a result of the impacts produced in the waste of energy, water pollution, and gas emissions. 


\section{$5 \quad$ Results and Discussion}

\subsection{Impact assessment}

For the characterization step of the impact assessment, the environmental indicator listed in the inventory table (Table 4) is translated into scores for each impact category, following the measurement with the indicators. To calculate the environmental impact of the process, the flows must be quantified and multiplied with their specific eco-indicator (Burkhart and Aurich, 2015). These indicators are estimated by following the methodologies of CML 2001 and USEtox. The CML 2001 is an impact assessment method developed by the Institute of Environmental Sciences of the University of Leiden (CML), which quantify the emissions of the cause-effect chain. The results of impact categories are grouped into midpoint categories. On the other hand, 
the USEtox methodology is an environmental model for the characterization of human and ecotoxicological impacts, which is defined by the factors of carcinogenic and non-carcinogenic with the measurement of $\mathrm{CTU}_{\mathrm{h}}$. Once linked all the materials, fluids, and energy flow, a collection of the data about inputs and outputs was done for the Investment Casting process. The Table 5 and the figures below, show the general inputs and outputs emissions data of the processes according to the amount substance classification.

Table 5

Output Inventory of general emissions data.

\begin{tabular}{|l|r|r|r|}
\multicolumn{1}{|c|}{ Outputs } & \multicolumn{1}{c|}{ IC } & \multicolumn{1}{c|}{ PMM } & \multicolumn{1}{c|}{ SLM } \\
\hline Emissions to sea water & $1.20 \mathrm{E}+05 \mathrm{~kg} \mathrm{eq}$. & $9.90 \mathrm{E}+03 \mathrm{~kg} \mathrm{eq}$ & $7.39 \mathrm{E}+04 \mathrm{~kg} \mathrm{eq}$ \\
\hline Deposited goods & $3.10 \mathrm{E}+04 \mathrm{~kg} \mathrm{eq}$ & $6.10 \mathrm{E}+04 \mathrm{~kg} \mathrm{eq}$ & $1.96 \mathrm{E}+04 \mathrm{~kg} \mathrm{eq}$ \\
\hline Emissions to air & $1.90 \mathrm{E}+05 \mathrm{~kg} \mathrm{eq}$ & $0.027 \mathrm{~kg} \mathrm{eq}$ & $1.48 \mathrm{E}+05 \mathrm{~kg}$ eq \\
\hline Emissions to fresh water & $3.50 \mathrm{E}+07 \mathrm{~kg} \mathrm{eq}$ & $4.50 \mathrm{E}+02 \mathrm{~kg} \mathrm{eq}$ & $2.1 \mathrm{E}+07 \mathrm{~kg}$ eq \\
\hline Emissions to agricultural soil & $0.0053 \mathrm{~kg} \mathrm{eq}$ & $3.80 \mathrm{E}+04 \mathrm{~kg} \mathrm{eq}$ & $0.0034 \mathrm{~kg} \mathrm{eq}$ \\
\hline Emissions to industrial soil & $0.078 \mathrm{~kg} \mathrm{eq}$ & $0.0017 \mathrm{~kg} \mathrm{eq}$ & $0.048 \mathrm{~kg} \mathrm{eq}$ \\
\hline
\end{tabular}

These data and information were used to feed the GaBi Software that simulates the process and gives sustainability information about specific metrics. The previously modeled process was used to define what the GaBi Software calls a "Process Diagram." The results of the simulation of the Precision Machining Manufacturing process are shown in Fig. 12. Similar diagrams were generated for the cases of Selective Laser Melting and Investment Casting process.

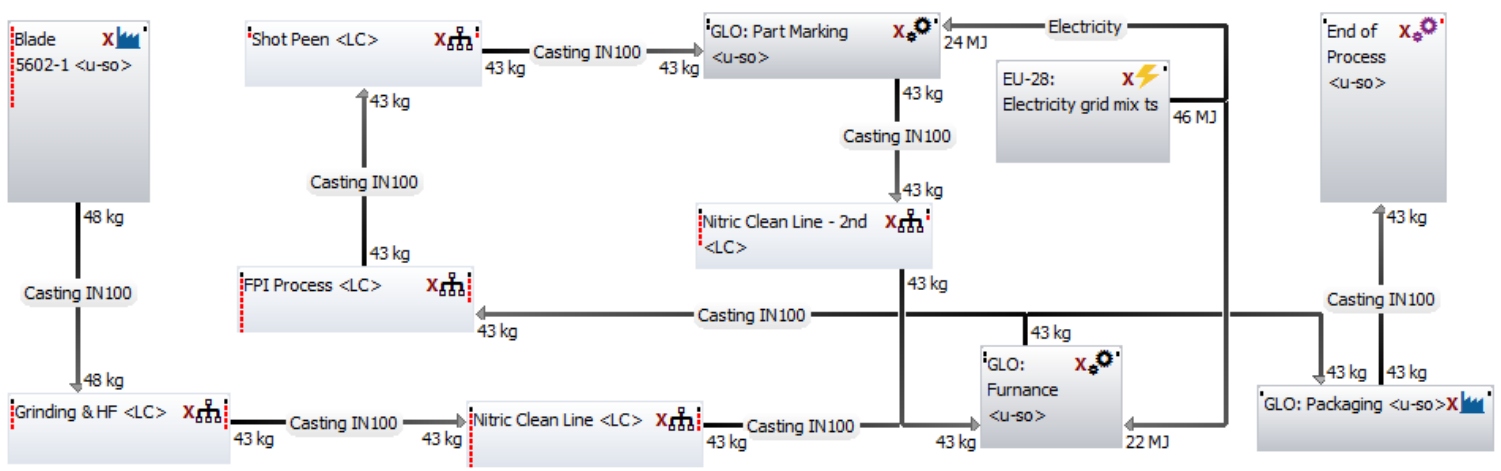

Fig. 12 Process diagram of Precision Machining Manufacturing (GaBi Software). 


\subsection{Environmental impacts}

According to the interpretation stage of the LCA standard, the inputs and outputs for each manufacturing process are quantified in order to obtain the sustainability indicators. The results of the simulation with $\mathrm{GaBi}$ Software helped to determine which stage of each manufacturing process has the worst ecological impact in terms of quantity of greenhouse gas emissions among others. Focusing on gas emissions, Table 6, shows the environmental impact for each manufacturing process analyzed and measured, as well, the reduction achieved using the process plan that considers AM against CM for a batch size of 600 parts. 
Table 6

Results of environmental impacts analysis.

\begin{tabular}{|c|c|c|c|c|c|c|}
\hline Indicators & GWP & $\mathbf{A P}$ & ODP & HTP & HT cancer & HT non-cancer \\
\hline Unit (Kg-eq.) & $\mathrm{CO}_{2}$ & $\mathrm{SO}_{2}$ & R11 & DCB & $\mathrm{CTU}_{\mathrm{h}}$ & $\mathrm{CTU}_{\mathrm{h}}$ \\
\hline Investment Casting & 4816.00 & 13.91 & $2.16 \mathrm{E}-07$ & 222.32 & $3.87 \mathrm{E}-06$ & $1.57 \mathrm{E}-05$ \\
\hline Precision Machining & $2,509.28$ & 6.64 & $1.00 \mathrm{E}-07$ & 100.84 & $1.93 \mathrm{E}-06$ & $7.80 \mathrm{E}-06$ \\
\hline Selective Laser Melting & $4,517.92$ & 12.75 & $1.96 \mathrm{E}-07$ & 204.84 & $3.53 \mathrm{E}-06$ & $1.16 \mathrm{E}-05$ \\
\hline Conventional Manufacturing & $7,325.28$ & 20.55 & $3.16 \mathrm{E}-07$ & 323.15 & 5.80E-06 & $2.35 \mathrm{E}-05$ \\
\hline Additive Manufacturing & $7,027.20$ & 19.39 & $2.96 \mathrm{E}-07$ & 305.68 & $5.46 \mathrm{E}-06$ & $1.94 \mathrm{E}-05$ \\
\hline Emission Reduction (\%) & $\overline{4}$ & $\overline{6}$ & $\overline{7}$ & $\overline{5}$ & $\overline{6}$ & 17 \\
\hline
\end{tabular}

In this case, the obtained results provide information about the potential toxicity of air, water and soil of each stage analyzed in the process of investment casting, precision machining and selective laser melting. If we want to analyze the manufacturing process of these parts from a global perspective, we need to consider the combination of individual manufacturing technologies. The results show the differences between the environmental sustainability analysis of Conventional Manufacturing and Additive Manufacturing of each environmental impact.

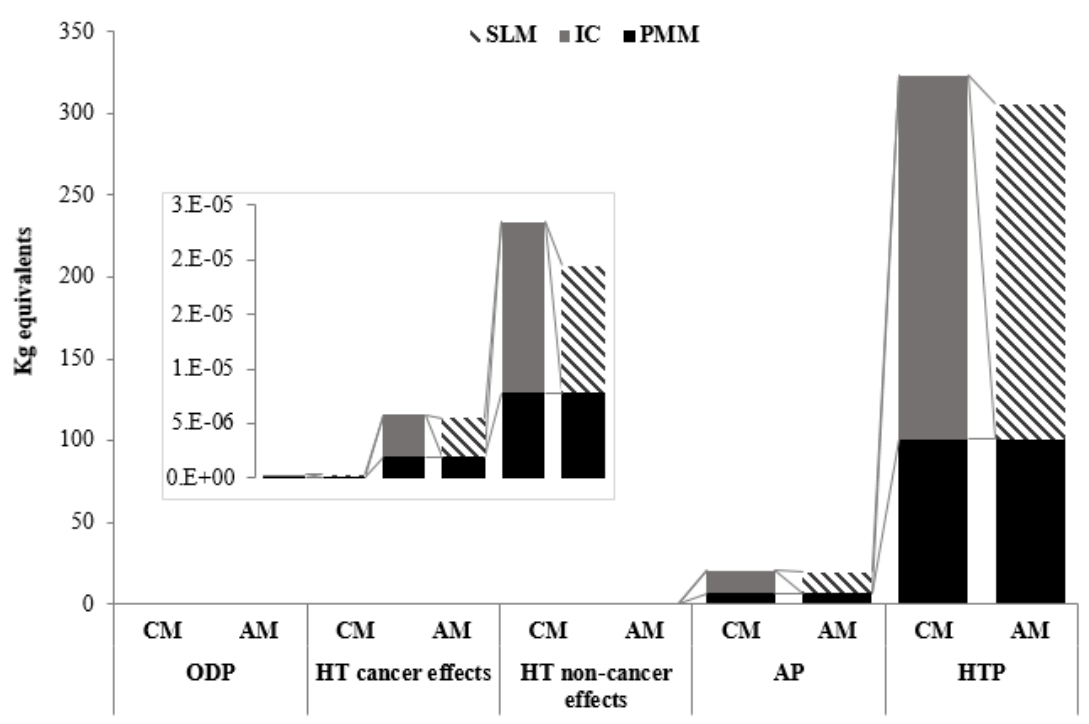

Fig. 13 Environmental impacts comparison between CM and AM, based in CML 2001- Jan2016. 


\subsection{Carbon footprint}

If we go deeper into the Global Warming Potential emissions, that is $\mathrm{CO}_{2}$; we can see from the data that the material input and the pouring operations are the main contributors to the gas emission (Table 7). In the process of Precision Machining Manufacturing, energy is directly consumed by heavy machinery, in which each stage in operation along the turbine blade manufacturing will be monitored.

Table 7

Energy consumption of Investment Casting Process.

\begin{tabular}{llrr}
\multicolumn{1}{c}{ Investment Casting Stage } & \multicolumn{1}{c}{ Amount } & Energy (kWh) & Kg CO $_{2}$-eq \\
Raw Material ${ }^{1}$ (Wilson et al., 2014) & $67.12 \mathrm{~kg}$ & 5214.42 & 2314.82 \\
\hline Pattern making tree & 600 parts & 443.93 & 197 \\
\hline Shell-making & 30 Pattern trees & 4842.90 & 2149 \\
\hline Investment Casting & $48.06 \mathrm{~kg}$ & 325.94 & 144.63 \\
\hline Refining and Pouring (Margolis et al., 1999) & $48.06 \mathrm{~kg}$ & 17.46 & 7.70 \\
\hline Cleaning \& Finishing & $48.06 \mathrm{~kg}$ & 8.69 & 3.85 \\
\hline Total & & $\mathbf{1 0 ~ 8 5 3 . 3 4}$ & $\mathbf{4 ~ 8 1 6}$ \\
\hline In literature review is called: ${ }^{1}$ Metal in bar stock form. & &
\end{tabular}

Thus, after knowing the energy consumption of each machine, it is important to specify the data information of energy and fluids consumption. The energy consumption of Precision Machining Manufacturing is illustrated in Table 8, and the energy consumption for Selective Laser Melting process is in

Table 9.

Table 8

Energy consumption of Precision Machining Manufacturing process.

\begin{tabular}{llrr}
\multicolumn{1}{c}{ Precision Machining Stage } & \multicolumn{1}{c}{ Amount } & Energy (kWh) & Kg $\mathbf{C O}_{2}$-eq. \\
Grinding & $48.06 \mathrm{~kg}$ & 4817.76 & 2140.49 \\
\hline Nitric Clean & $43.26 \mathrm{~kg}(2 \mathrm{hr})$. & 145.78 & 302.98 \\
\hline FPI Process & $43.26 \mathrm{~kg}$ & 59.31 & 14.27 \\
\hline Shot peen & $43.26 \mathrm{~kg}$ & 22.19 & 9.85 \\
\hline Nitric Clean Second & $43.26 \mathrm{~kg}(0.8 \mathrm{hr})$. & 116.63 & 36.06 \\
\hline Marking \& Packaging & $43.26 \mathrm{~kg}$ & 6.75 & 5.64 \\
\hline Total & & $\mathbf{5 1 6 8 . 4 2}$ & $\mathbf{2 5 0 9 . 2 9}$ \\
\hline
\end{tabular}




\section{Table 9}

Energy consumption of Selective Laser Melting Manufacturing process.

\begin{tabular}{lrrr}
\multicolumn{1}{c}{ Selective Laser Melting } & Amount & Energy (kWh) & Kg $\mathbf{C O}_{2}$-eq. \\
Raw Material ${ }^{1}$ (Wilson et al., 2014) & $48.06 \mathrm{~kg}$ & 3732.81 & 1656.38 \\
\hline Powder Production (Margolis et al. 1999) & $48.06 \mathrm{~kg}$ & 742.06 & 329.28 \\
\hline SLM Process & & 5706.70 & 2532.26 \\
\hline Total & $\mathbf{1 0 ~ 1 8 1 . 5 7}$ & $\mathbf{4 5 1 7 . 9 2}$ \\
\hline In literature review is called: ${ }^{1}$ Metal in bar stock form. & & &
\end{tabular}

The methodology implemented here is CML 2001 with the last data actualization in January 2016, which provides the results of Global Warming Potential over 100 years in $\mathrm{kg} \mathrm{CO}_{2}$ equivalent emissions (GWP 100). The concept of GWP 100 refers to the equivalence in all the emissions released in the process that cause hazardous effects in a period of 100 years. The comparative results of the carbon footprint from the cradle-togate analysis with a batch of 600 parts between CM and AM are illustrated in Fig. 14. Conventional Manufacturing has a total of $7325 \mathrm{~kg} \mathrm{CO}_{2}$ and Additive Manufacturing a total of $7027 \mathrm{~kg} \mathrm{CO}_{2}$. Again, in the assessment of both alternatives, we can see that Additive Manufacturing achieves less Global Warning Emissions with a reduction of $4 \%$.

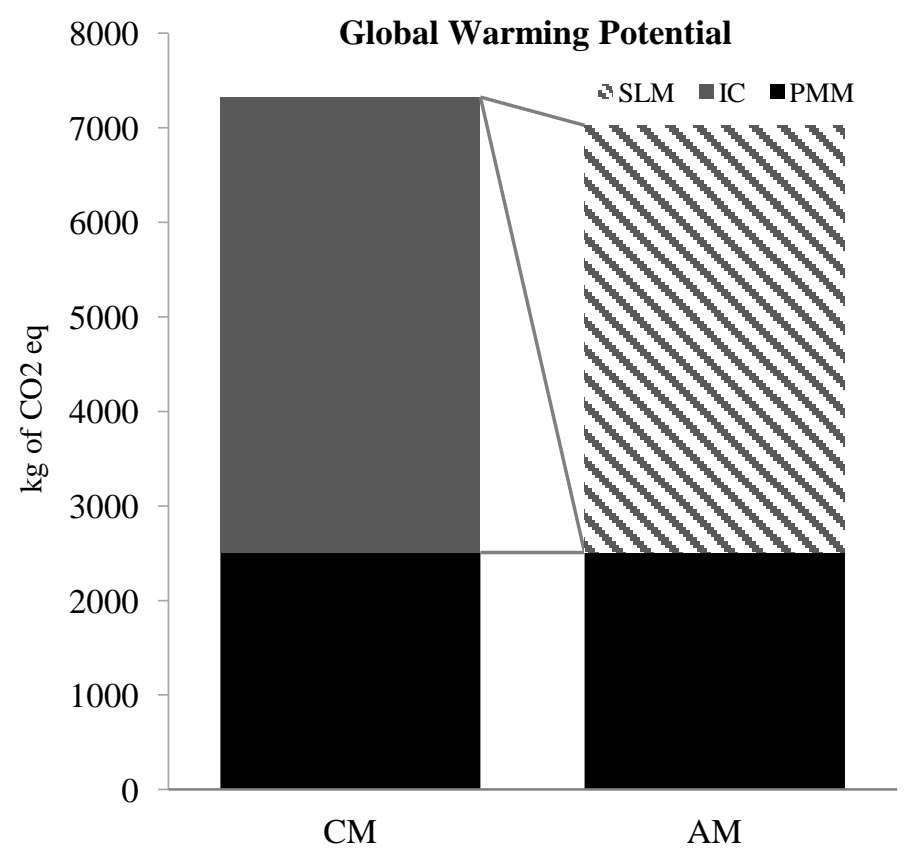


Fig. 14 Comparison of carbon footprint, based in CML 2001-Jan 2016, GWP 100.

\section{Sensitivity Analysis}

The sensitivity analysis was performed on the input data energy and assumptions of LCA in order to estimate 2 different scenarios. The first scenario it is assumed a forth grinder machine for contour surface, the scenario contemplates another grinding operation because of roughness of the 3D metal part. In the second scenario, it is assumed a higher grinding time for countersink with the HASS machine, it is estimate $5 \pm$ $0.25 \mathrm{~min}$ min per part instead of $1.4 \pm 0.25 \mathrm{~min}$.

Table 10

Scenarios data for Sensibility Analysis.

\begin{tabular}{|c|c|c|c|c|c|c|}
\hline \multirow{9}{*}{$\begin{array}{l}\text { \# } \\
\stackrel{\#}{\tilde{E}}\end{array}$} & Stages & Operations & $\begin{array}{l}\text { Time } \\
(\mathbf{h r})\end{array}$ & kWh & $\begin{array}{c}\text { kWh } \\
600 \mathrm{Pz}\end{array}$ & kg CO2 \\
\hline & \multirow{7}{*}{$\begin{array}{c}\text { Grinding and } \\
\mathrm{HF}\end{array}$} & Grind Root Form & 75 & 19.88 & 1490.70 & 662.31 \\
\hline & & Tip/slot & 75 & 19.88 & 1490.70 & 662.31 \\
\hline & & Z Form & 75 & 19.88 & 1490.70 & 662.31 \\
\hline & & Contour Surface & 75 & 19.88 & 1490.70 & 662.31 \\
\hline & & Finishing & 14.3 & 0.60 & 8.53 & 3.8 \\
\hline & & Coordinate Measuring Machine & 50 & 5.27 & 263.46 & 117 \\
\hline & & Hand Finish & 75 & 0.98 & 73.66 & 32.7 \\
\hline & \multicolumn{2}{|r|}{ Total } & 439 & 86.35 & 6308.45 & 2802.80 \\
\hline \multirow{7}{*}{ 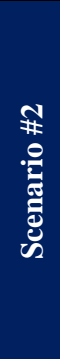 } & \multirow{6}{*}{$\begin{array}{c}\text { Grinding and } \\
\mathrm{HF}\end{array}$} & Grind Root Form & 75 & 19.88 & 1490.70 & 662.31 \\
\hline & & Tip/slot & 75 & 19.88 & 1490.70 & 662.31 \\
\hline & & Z Form & 75 & 19.88 & 1490.70 & 662.31 \\
\hline & & Finishing & 50 & 0.60 & 29.85 & 13.26 \\
\hline & & Coordinate Measuring Machine & 50 & 5.27 & 263.46 & 117 \\
\hline & & Hand Finish & 75 & 0.98 & 73.66 & 32.7 \\
\hline & & Total & 400 & 66.48 & 4839.07 & 2149.96 \\
\hline
\end{tabular}

Sensitivity analyses are provided to determine how changes in the energy consumption and finish machining for 3D metal parts could affect the life cycle of Additive Manufacturing in terms of Carbon Footprint. The comparative chart is shown in Fig. 15. The Scenario 1 in comparison with the Original results shows an increase of $4.17 \%$ in $\mathrm{kg} \mathrm{CO}^{2}$. Meanwhile, the scenario 2 present a decrease of $5.11 \%$. More studies are necessary to determinate if adding more machining time to 3D parts are useful to improve the surface quality and might reduce the carbon footprint. 


\section{Conclusions and Future Works}

The present study provides an environmental analysis of Selective Laser Melting (SLM) and compares it with Conventional Manufacturing that applies Investment Casting Techniques for Turbine Blades Manufacturing. The resultant analysis shows that it is possible to reduce global warming and energy consumption with the proposed Additive Manufacturing based process plan.

The analysis shows that the reduction of the carbon footprint and environmental impact in the use of Additive Manufacturing is of approximately 4\% in comparison to Conventional Manufacturing. The observation of the results also shows that the energy consumption to manufacture a batch of 600 turbine blade parts in a conventional way is clearly higher than with Additive Manufacturing. Therefore, this last has a quantified potential to reduce the environmental impacts and to reduce the carbon footprint. However, after performing a sensitivity analysis it is acknowledged that any change in the surface roughness of the preform to be machined will affect the environmental performance of the whole process chain and therefore the SLM process should be properly calibrated.

Design for Manufacturing and Manufacturing Process Planning decisions can optimize many factors for the whole product lifecycle. The collection of data of this work can be a piece of crucial information for manufacturing companies in order to have a greater understanding of the relationship between emergent technologies and the environmental impacts. The present study has implications in decision-making because 
from our point of view data and information will help to companies with similar manufacturing process plans derived from similar parts regarding geometry and material. Design engineers will also have further information apart from the functional and mechanical performances advantages of powder bed fusion technologies.

We could add that the findings also support other studies that recommend the adoption of Additive Manufacturing in order not only to improve design features but also to reduce the environmental impact in the aerospace parts manufacturing. The implementation of AM technologies to produce aerospace components can improve the process not only in sustainability issues but also in technological ones. This emerging technology that is available now will replace some stages of production processes, thus ensuring optimization and high productivity to reduce the companies supply chain cost and delivery times.

More work is needed to analyze the results sensitivity in regard to a modification of process parameters. For example, within the selected additive manufacturing machine we can adjust parameters like laser power, exposure time, point distance and building speed. A design of experiments will allow optimizing the environmental metrics beyond the initial results. The part geometry and surface quality requirements are also key issues when selecting the process because the energy consumption is affected by processing time.

As future work, it is intended the cradle-to-gate LCA of the set of processes studied here, and including more scenarios regarding the production of powder with different techniques like gas atomization, plasma atomization and water atomization among others. Additionally, Additive Manufacturing of functional parts will require the use of post-processing technologies like heat treatment and hot isostatic pressing, which need to be taken into account for the entire environmental analysis.

\section{References}

Baumers, M., Tuck, C., Hague, R., Ashcroft, I., Wildman, R., 2010. A comparative study of metallic additive manufacturing power consumption. Solid Free. Fabr. Symp. 278-288.

Baumers, M., Tuck, C., Wildman, R., Ashcroft, I., Hague, R., 2011. Energy inputs to additive manufacturing: Does capacity utilization matter? Solid Free. Fabr. Symp. 30-40. https://doi.org/10.1017/CBO9781107415324.004

Burkhart, M., Aurich, J.C., 2015. Framework to predict the environmental impact of additive manufacturing in the life cycle of a commercial vehicle. Procedia CIRP 29, 408-413. 
Conner, B.P., Manogharan, G.P., Martof, A.N., Rodomsky, L.M., Rodomsky, C.M., Jordan, D.C., Limperos, J.W., 2014. Making sense of 3-D printing: Creating a map of additive manufacturing products and services. Addit. Manuf. 1, 64-76. https://doi.org/10.1016/j.addma.2014.08.005

Degarmo, E.P., J T. Black, Kohser, R. a, 2003. Materials and Processes in Manufacturing. Mater. Process Manuf. 383.

Europoles $\mathrm{GmbH} \& \mathrm{Co.KG}$, n.d. Environmental comparison of spun-concrete columns and composite steel columns.

Faludi, J., Baumers, M., Maskery, I., Hague, R., 2017. Environmental Impacts of Selective Laser Melting: Do Printer, Powder, Or Power Dominate? J. Ind. Ecol. 21, S144-S156. https://doi.org/10.1111/jiec.12528

Gebler, M., Schoot Uiterkamp, A.J.M., Visser, C., 2014. A global sustainability perspective on 3D printing technologies. Energy Policy 74, 158-167. https://doi.org/10.1016/j.enpol.2014.08.033

Huang, R., Riddle, M., Graziano, D., Warren, J., Das, S., Nimbalkar, S., Cresko, J., Masanet, E., 2016. Energy and emissions saving potential of additive manufacturing: the case of lightweight aircraft components. J. Clean. Prod. 135, 1559-1570. https://doi.org/10.1016/j.jclepro.2015.04.109

Ingarao, G., Priarone, P.C., Deng, Y., Paraskevas, D., 2018. Environmental modelling of aluminium based components manufacturing routes: Additive manufacturing versus machining versus forming. J. Clean. Prod. 176, 261-275. https://doi.org/10.1016/j.jclepro.2017.12.115

International Organization for Standardization, 2006. ISO 14044:2006-Environmental management. Life cycle assessment. Requirements and guidelines 55 .

Kellens, K., Mertens, R., Paraskevas, D., Dewulf, W., Duflou, J.R., 2017. Environmental Impact of Additive Manufacturing Processes: Does AM Contribute to a More Sustainable Way of Part Manufacturing? Procedia CIRP 61, 582-587. https://doi.org/10.1016/j.procir.2016.11.153

Le Bourhis, F., Kerbrat, O., Dembinski, L., Hascoet, J.-Y., Mognol, P., 2014. Predictive Model for Environmental Assessment in Additive Manufacturing Process. Procedia CIRP 15, 26-31. https://doi.org/10.1016/j.procir.2014.06.031

Lenzen, M., Murray, S.A., Korte, B., Dey, C.J., 2003. Environmental impact assessment including indirect effects - A case study using input-output analysis. Environ. Impact Assess. Rev. 23, 263-282. 
Margolis, N., Jamison, K., Dove, L., 1999. Energy and environmental profile of the U.S. metalcasting industry.

Morrow, W.R., Qi, H., Kim, I., Mazumder, J., Skerlos, S.J., 2007. Environmental aspects of laser-based and conventional tool and die manufacturing. J. Clean. Prod. 15, 932-943. https://doi.org/10.1016/j.jclepro.2005.11.030

Nyamekye, P., Leino, M., Piili, H., Salminen, A., 2015. Overview of Sustainability Studies of CNC Machining and LAM of Stainless Steel. Phys. Procedia 78, 367-376. https://doi.org/10.1016/j.phpro.2015.11.051

Paris, H., Mokhtarian, H., Coatanéa, E., Museau, M., Ituarte, I.F., 2016. Comparative environmental impacts of additive and subtractive manufacturing technologies. CIRP Ann. - Manuf. Technol. 65, 29-32. https://doi.org/10.1016/j.cirp.2016.04.036

Pattnaik, S., Karunakar, D.B., Jha, P.K., 2012. Developments in investment casting process - A review. J. Mater. Process. Technol. 212, 2332-2348. https://doi.org/10.1016/j.jmatprotec.2012.06.003

Priarone, P.C., Ingarao, G., 2017. Towards criteria for sustainable process selection: On the modelling of pure subtractive versus additive/subtractive integrated manufacturing approaches. J. Clean. Prod. 144, 57-68. https://doi.org/10.1016/j.jclepro.2016.12.165

Read, N., Wang, W., Essa, K., Attallah, M.M., 2015. Selective laser melting of AlSi10Mg alloy: Process optimisation and mechanical properties development. Mater. Des. 65, 417-424. https://doi.org/10.1016/j.matdes.2014.09.044

Serres, N., Tidu, D., Sankare, S., Hlawka, F., 2011. Environmental comparison of MESO-CLAD process and conventional machining implementing life cycle assessment. J. Clean. Prod. 19, 1117-1124. https://doi.org/10.1016/j.jclepro.2010.12.010

The British Standards Institution, 2011. PUBLICLY AVAILABLE SPECIFICATION PAS 2050: 2011 Specification for the assessment of the life cycle greenhouse gas emissions of goods and services. System 1-45. https://doi.org/978 0580713828

Vilaro, T., Colin, C., Bartout, J.D., Nazé, L., Sennour, M., 2012. Microstructural and mechanical approaches of the selective laser melting process applied to a nickel-base superalloy. Mater. Sci. Eng. A 534, 446- 
451. https://doi.org/10.1016/j.msea.2011.11.092

Wiedmann, T. y J.M., 2007. A Definition of Carbon Footprint. ISA UK Research Report. 1-7.

Wilson, J.M.M., Piya, C., Shin, Y.C.Y.C., Zhao, F.F., Ramani, K., 2014. Remanufacturing of turbine blades by laser direct deposition with its energy and environmental impact analysis. J. Clean. Prod. 80, 170178. https://doi.org/10.1016/j.jclepro.2014.05.084

Wong, K. V., Hernandez, A., 2012. A Review of Additive Manufacturing. ISRN Mech. Eng. 2012, 1-10. https://doi.org/10.5402/2012/208760 


\section{List of Figures}

Fig. 1 Aircraft distribution of (a) weight used, and (b) cost production. ............................................... 3

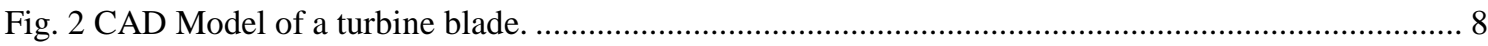

Fig. 3 Turbine blade Manufacturing process plan for aircraft engines. ….................................................. 8

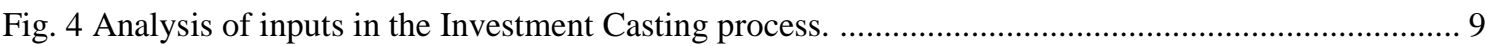

Fig. 5 Analysis of inputs of the Precision Machining Manufacturing process. ........................................ 11

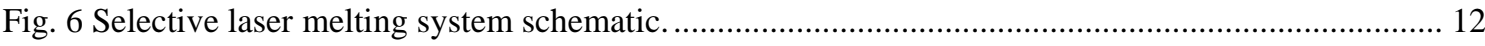

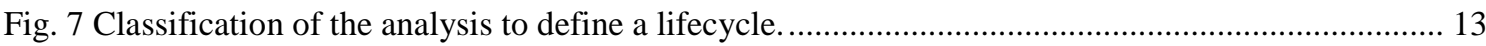

Fig. 8 Schematization of the case study to be compared, (a) CM, and (b) AM. ....................................... 14

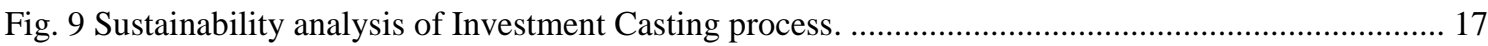

Fig. 10 Sustainability Analysis of Precision Machining Manufacturing. .................................................. 18

Fig. 11 Sustainability analysis of Selective Laser Melting process. ........................................................... 19

Fig. 12 Process diagram of Precision Machining Manufacturing (GaBi Software)................................... 20

Fig. 13 Environmental impacts comparison between CM and AM, based in CML 2001- Jan2016.......... 22

Fig. 14 Comparison of carbon footprint, based in CML 2001-Jan 2016, GWP 100................................... 25

Fig. 15 Comparison of carbon footprint, based on different scenarios. ................................................... 26 


\section{List of Tables}

Table 1 A literature review of LCA and its comparison between AM and CNC manufacturing. ................ 5

Table 2 Literature review focus on works related with the other classification of metal AM processes...... 7

Table 3 Description of environmental impact indicators to be measured in the experimental procedure

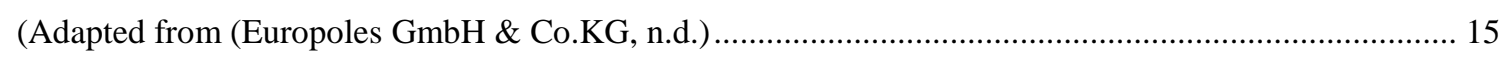

Table 4 Inventory data to be considered for selected metrics in each manufacturing technology. ............. 16

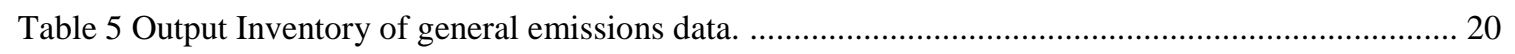

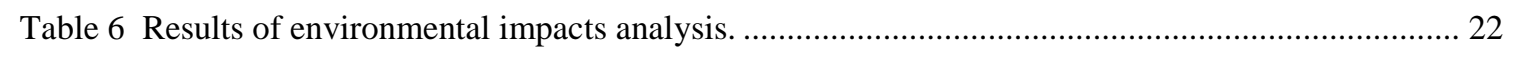

Table 7 Energy consumption of Investment Casting Process .............................................................. 23

Table 8 Energy consumption of Precision Machining Manufacturing process. .......................................... 23

Table 9 Energy consumption of Selective Laser Melting Manufacturing process.................................... 24 


\section{Appendix}

\section{Appendix Table 1}

Quantitative Data Collection of electricity in Investment Casting.

\begin{tabular}{|c|c|c|c|}
\hline Stages & Machines & kWh & kWh 600pz \\
\hline Raw Material & Fabrication of raw metal & & 5214.42 \\
\hline \multirow{4}{*}{ Patterns making tree } & Wax model design & N.C & \multirow{4}{*}{443.93} \\
\hline & Wax mold fabrication & 4.93 & \\
\hline & Wax injection & 4.93 & \\
\hline & Pattern assembly & 4.93 & \\
\hline \multirow{2}{*}{ Shell-making } & Refractory slurry and grain & 43.05 & \multirow{2}{*}{4842.89} \\
\hline & Dry & 118.38 & \\
\hline Investment Casting & Investment Casting & & 325.94 \\
\hline Refining and Pouring & Pouring & & 17.46 \\
\hline \multirow{4}{*}{ Cleaning \& Finishing } & Knock out / shakeout & 1.25 & \multirow{4}{*}{8.69} \\
\hline & Cleaning rotatory system & 1.25 & \\
\hline & Cut off & 2.27 & \\
\hline & Grinding & 3.92 & \\
\hline
\end{tabular}

\section{Appendix Table 2}

Quantitative Data Collection of electricity in Precision Machining Manufacturing.

\begin{tabular}{|c|c|c|c|}
\hline Stages & Operations & $\mathbf{k W h}$ & $\mathrm{kWh} 600 \mathrm{Pz}$ \\
\hline \multirow{6}{*}{ Grinding and HF } & Grind Root Form & 19.876 & 1490.7 \\
\hline & Tip/slot & 19.876 & 1490.7 \\
\hline & Z Form & 19.876 & 1490.7 \\
\hline & Finishing & 0.597 & 8.53 \\
\hline & Coordinate Measuring Machine & 5.269 & 263.46 \\
\hline & Hand Finish & 0.982 & 73.66 \\
\hline \multirow{5}{*}{ Nitric Clean Line } & Furnance & \multirow{5}{*}{36.45} & \multirow{5}{*}{145.78} \\
\hline & Pumping system & & \\
\hline & Scrubber VIRON & & \\
\hline & Feeding boards & & \\
\hline & Tanks (10 tanks) & & \\
\hline \multirow{7}{*}{ FPI Process } & Penetrating impregnation & \multirow{7}{*}{14.83} & \multirow{7}{*}{59.31} \\
\hline & Prewash & & \\
\hline & Emulsifying tank & & \\
\hline & Postwash & & \\
\hline & Resistance drying furnace & & \\
\hline & Revealed cabin & & \\
\hline & FPI Inspection & & \\
\hline \multirow{4}{*}{ Final Operation } & Shot Peen & 4.44 & 22.19 \\
\hline & Part Marking & 0.23 & 6.75 \\
\hline & Finish Visual Inspection & 0 & 0 \\
\hline & Nitric Clean Second Line & 14.58 & 116.63 \\
\hline
\end{tabular}




\section{Appendix Table 3}

Quantitative Data Collection of electricity in Selective Laser Melting.

\begin{tabular}{|c|c|c|}
\hline Machine & $\mathbf{k W h}$ & $\mathbf{k W h} \mathbf{6 0 0 \mathbf { p z }}$ \\
\hline Feeding boards & 28.141 & 8442.43 \\
\hline Cooling Unit & 1.552 & 465.58 \\
\hline Powder Sieving Station & 0.030 & 9.07 \\
\hline Inert Gas-Generator & 0.515 & 154.56 \\
\hline EdNiCon Workbench & 0.016 & 4.89 \\
\hline Metal in bar stock form & & 3732.81 \\
\hline Powder Production & & 742.06 \\
\hline
\end{tabular}

Appendix Table 4

Quantitative Data Collection of materials in Turbine Blade Manufacturing.

\begin{tabular}{|c|c|c|}
\hline Area & Operation & Material* (kg.) \\
\hline \multicolumn{3}{|c|}{ *Raw Material } \\
\hline IC & Metal in bar & 67.12 \\
\hline PMM & Casting & 48.06 \\
\hline SLM & Powder metal & 70.51 \\
\hline \multicolumn{3}{|c|}{ *Refractory Slurry } \\
\hline \multirow{2}{*}{ Shell Making } & Ceramic & 16.66 \\
\hline & Slurry & 16.66 \\
\hline \multicolumn{3}{|c|}{$*$ Wax } \\
\hline Pattern making tree & Wax injection & 2.40 \\
\hline \multicolumn{3}{|c|}{ *Casting Weight } \\
\hline \multirow[t]{5}{*}{ Grinding and $\mathrm{HF}$} & Grind Root Form & 48.06 \\
\hline & Grind wire & 44.34 \\
\hline & Grind Z Form & 43.68 \\
\hline & HASS & 43.32 \\
\hline & Finished Part & 43.26 \\
\hline \multicolumn{3}{|c|}{ *Cast Steel Shot } \\
\hline Shot Peen & Shot Peen & 4.25 \\
\hline
\end{tabular}




\section{Appendix Table 5}

Quantitative Data Collection of fluids in Precision Machining Manufacturing.

\begin{tabular}{|c|c|c|c|}
\hline Area & Operation & Water (L) & Fluids* (L) \\
\hline \multicolumn{4}{|c|}{ *Lubricants } \\
\hline \multirow[t]{6}{*}{ Grinding and $\mathrm{HF}$} & Grind Root Form & 250 & 11.88 \\
\hline & Tip/slot & 187.5 & 7.50 \\
\hline & Z Form & 206.25 & 14.09 \\
\hline & Finishing & 20 & 2 \\
\hline & $\begin{array}{l}\text { Coordinate Measuring } \\
\text { Machine }\end{array}$ & 0 & 0 \\
\hline & Hand Finish & 0 & 0 \\
\hline \multicolumn{4}{|c|}{ *Chemicals } \\
\hline \multirow[t]{10}{*}{ Nitric Clean Line } & Tank \#101 & 577.51 & 115 \\
\hline & Tank \#102 & 577.51 & 0 \\
\hline & Tank \#103 & 577.51 & 0 \\
\hline & Tank \#104 & 577.51 & 115 \\
\hline & Tank \#105 & 577.51 & 0 \\
\hline & Tank \#106 & 577.51 & 0 \\
\hline & Tank \#107 & 577.51 & 115 \\
\hline & Tank \#108 & 577.51 & 0 \\
\hline & Tank \#109 & 577.51 & 0 \\
\hline & Tank \#110 & 577.51 & 0 \\
\hline \multicolumn{4}{|c|}{ *Penetrant Liquids } \\
\hline \multirow[t]{7}{*}{ FPI Process } & Penetrating impregnation & 0 & 15 \\
\hline & Prewash & 150 & 0 \\
\hline & Emulsifying tank & 150 & 10 \\
\hline & Postwash & 150 & 0 \\
\hline & Resistance drying & 0 & 0 \\
\hline & Revealed cabin & 0 & 2.5 \\
\hline & FPI Inspection & 0 & 0 \\
\hline
\end{tabular}


Wednesday, November $5^{\text {th }}, 2018$

"Environmental Analysis of Selective Laser Melting in the Manufacturing of Aeronautical Turbine Blades"

Dear editor of the Journal of Cleaner Production,

Please find enclosed the research highlights of the above candidate paper

- Process Modelling of Additive and Conventional Aerospace Manufacturing

- Data mining and simulation of manufacturing operations with a LCA tool

- Analysis of manufacturing process plan with Selective Laser Melting

- Sustainability Analysis of Investment Casting compared to Selective Laser Melting

Looking forward to hearing from you

Yours sincerely,

Prof. Dr. Carlos Vila

Manufacturing Engineering

Department of Mechanical Engineering and Materials

Polytechnic University of Valencia

Camino de Vera, $\mathrm{s} / \mathrm{n}$.

46022 VALENCIA. SPAIN

Tel.: (+34) 963877622 (Ext:76221)

email: carvipas@upv.es 

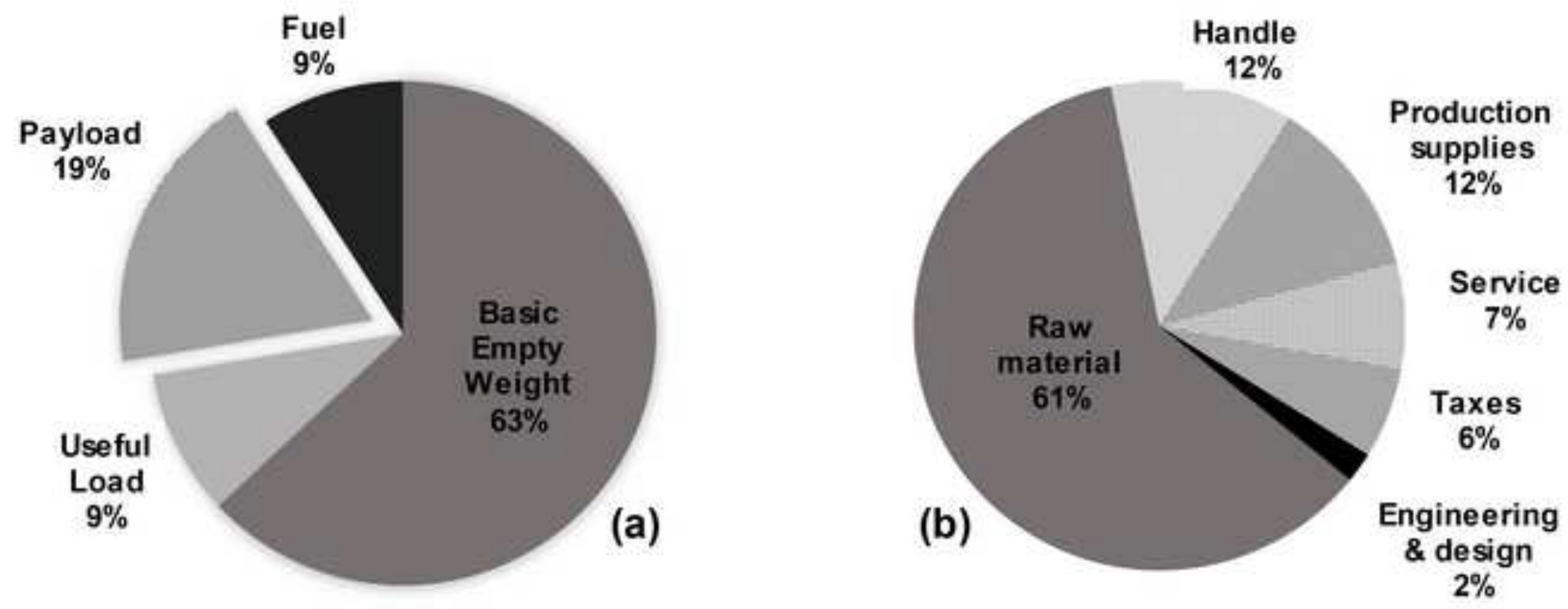

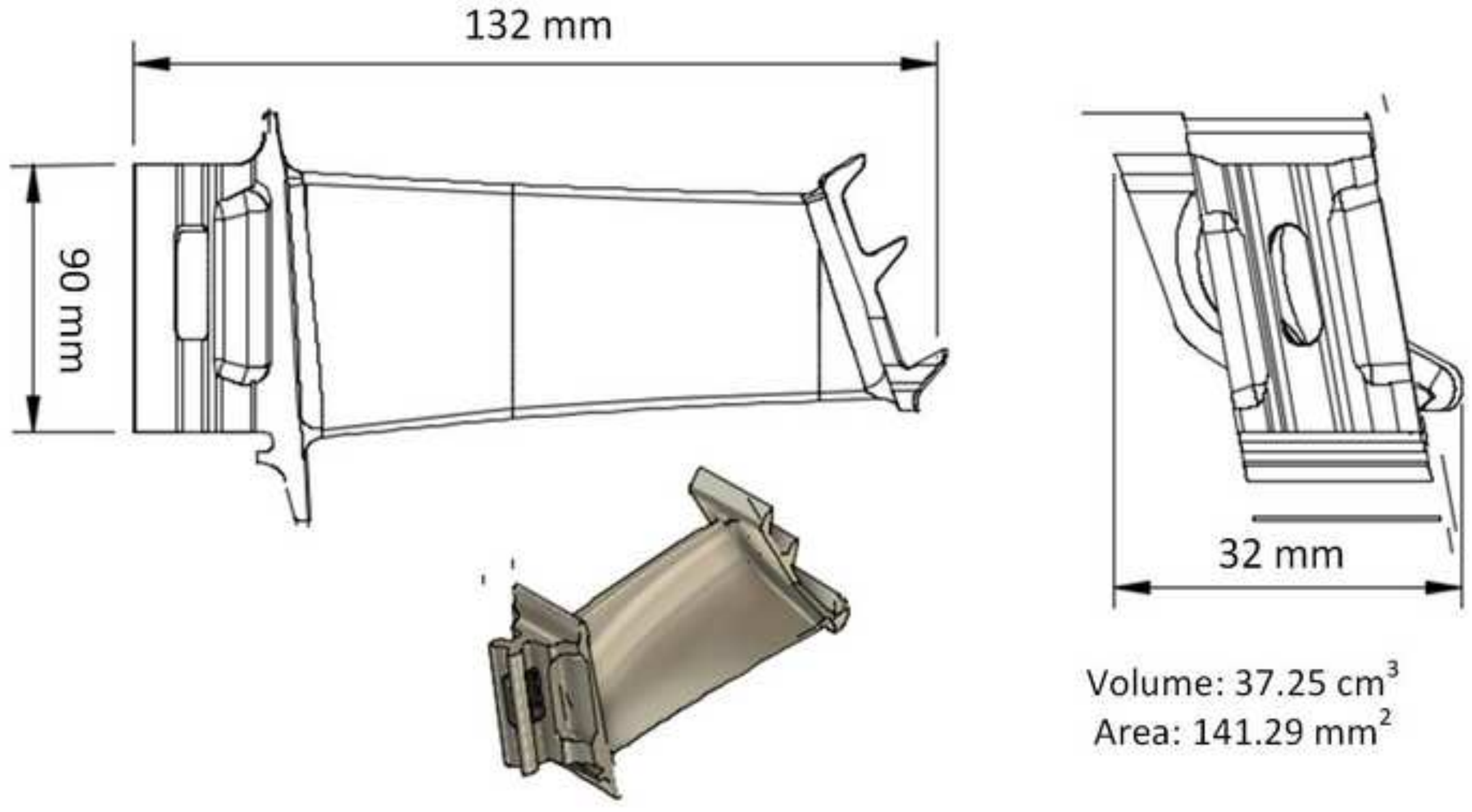

Volume: $37.25 \mathrm{~cm}^{3}$ Area: $141.29 \mathrm{~mm}^{2}$ 


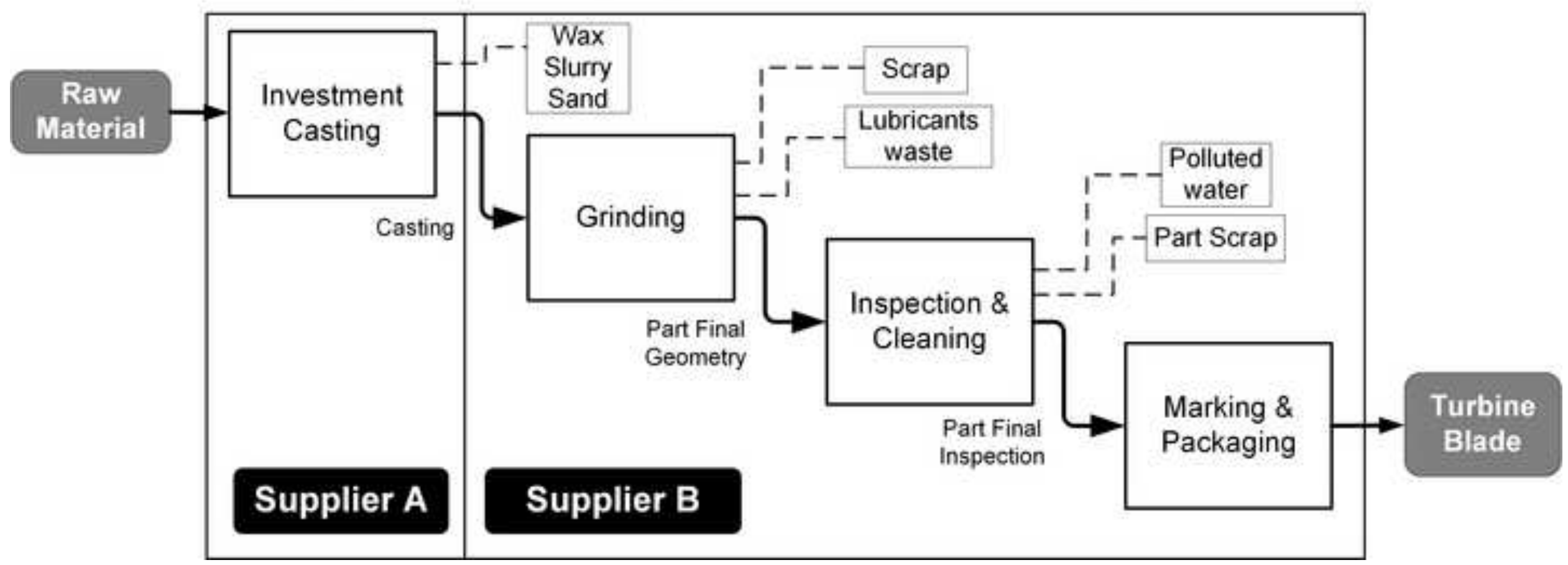




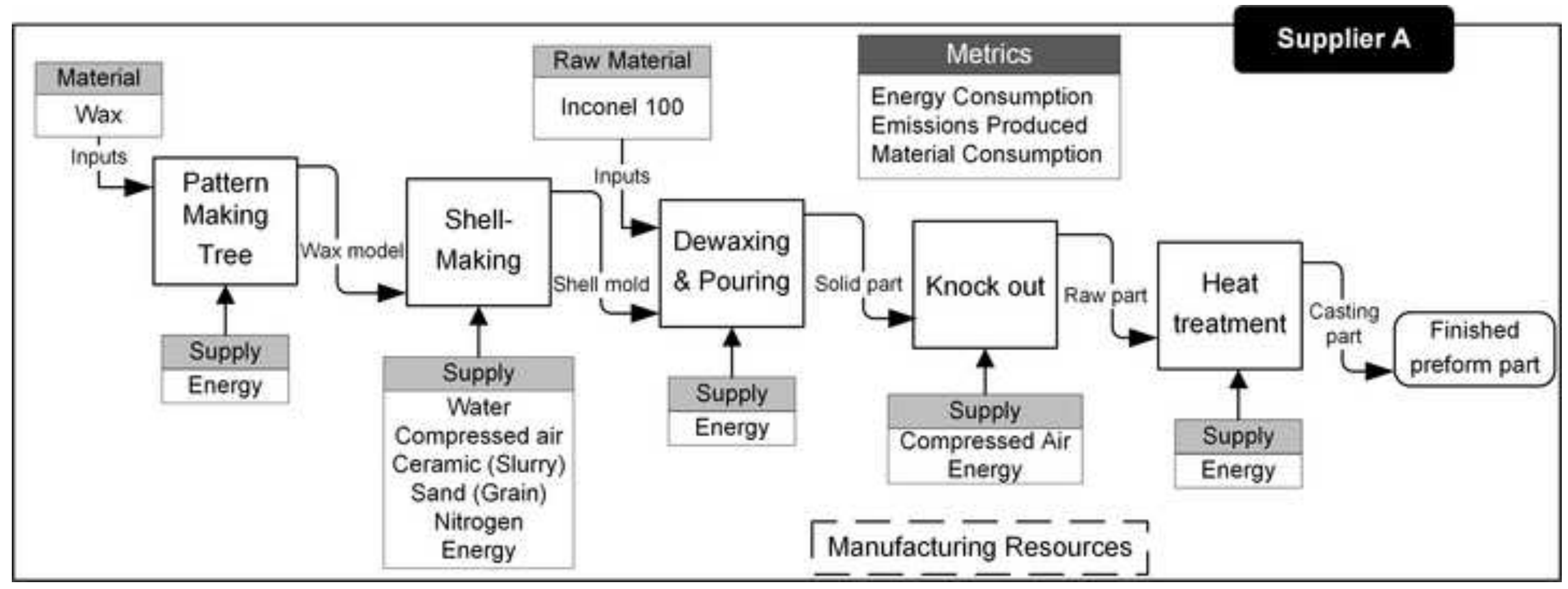


Click here to download high resolution image

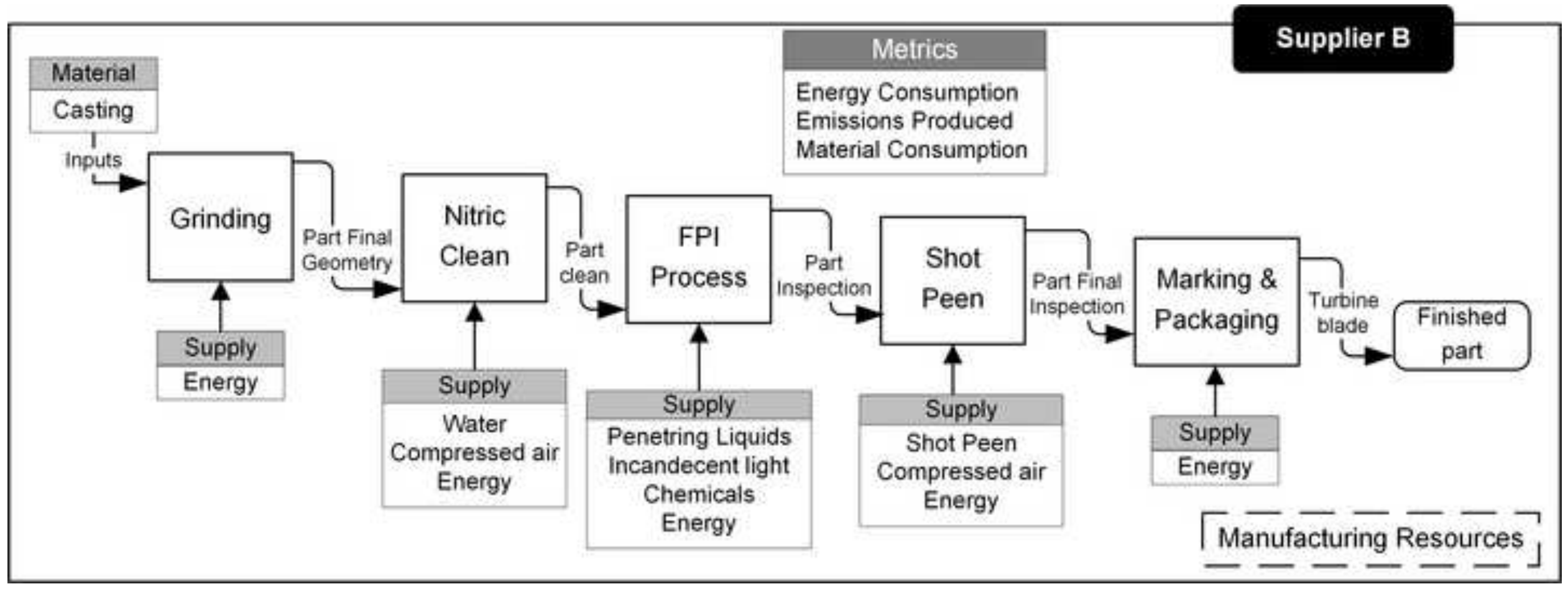


Laser melting of

powder material
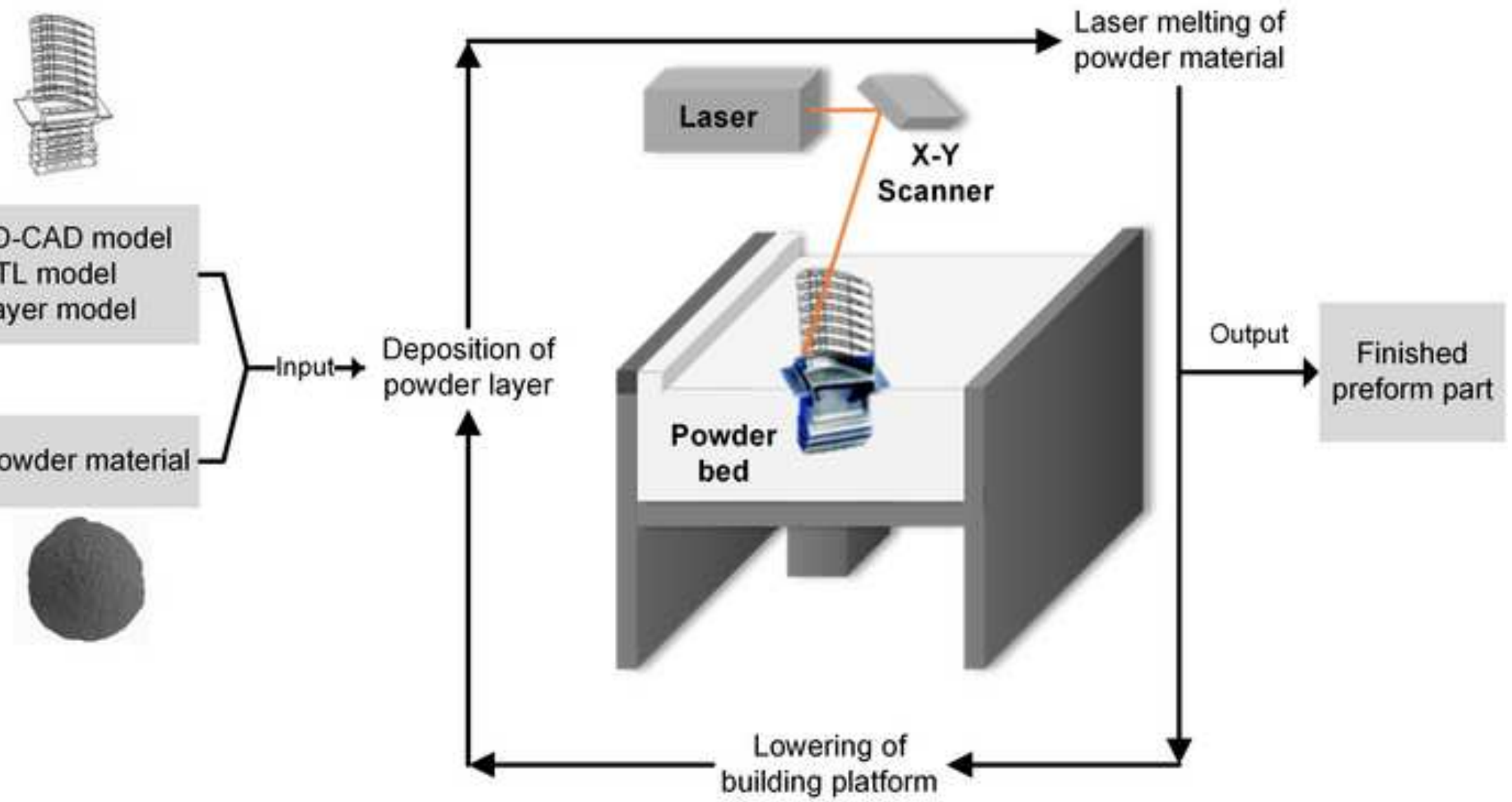

STL model

- Layer model

Powder material

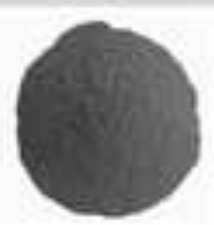

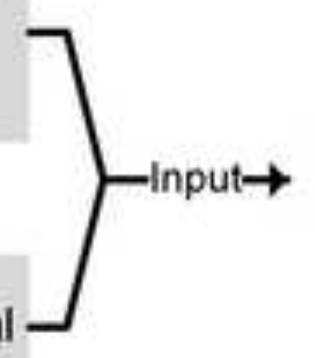

Deposition of

rayer

building platform 
Click here to download high resolution image

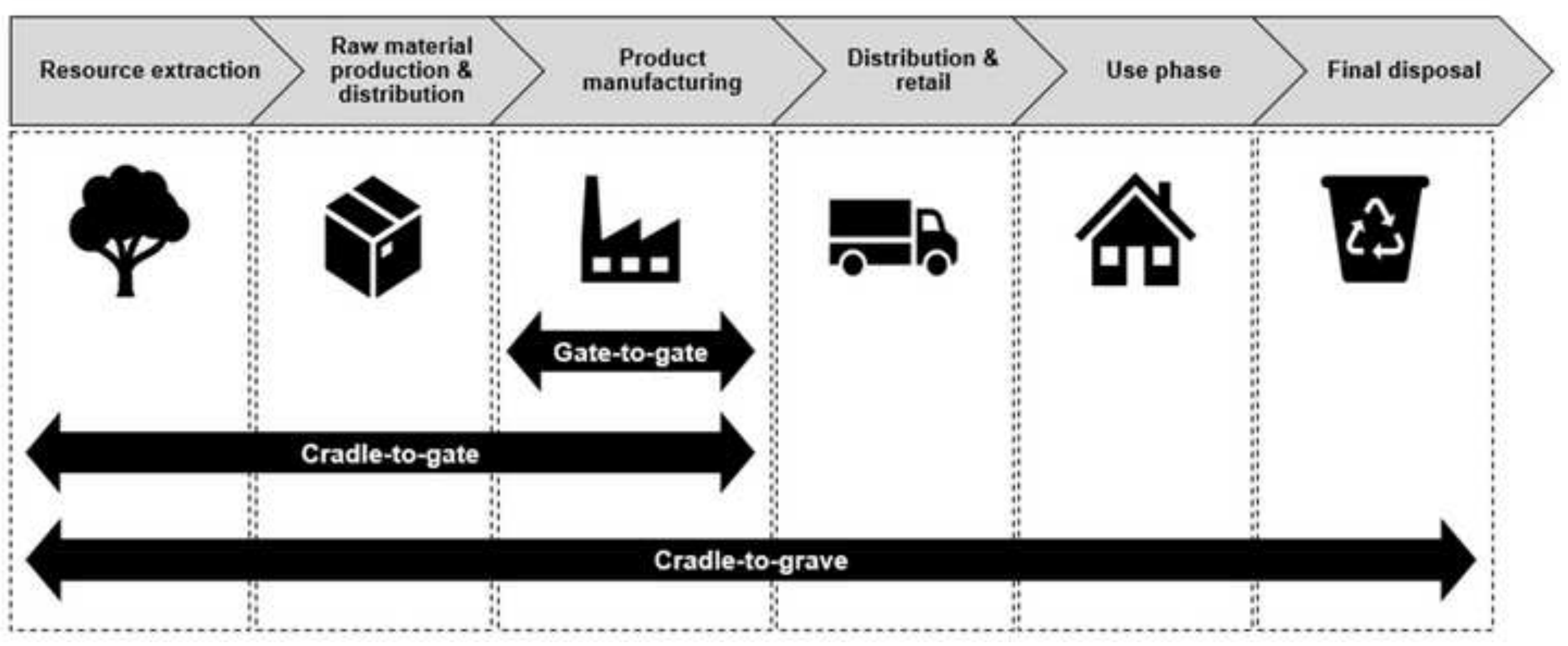

Click here to download high resolution image 


\section{Turbine Blade Manufacturing}

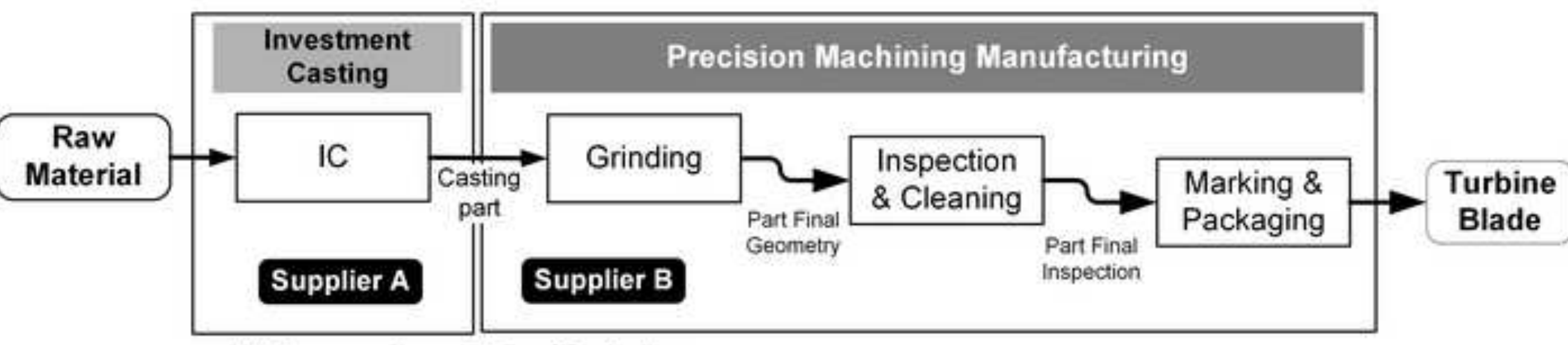

(a) Conventional Manufacturing

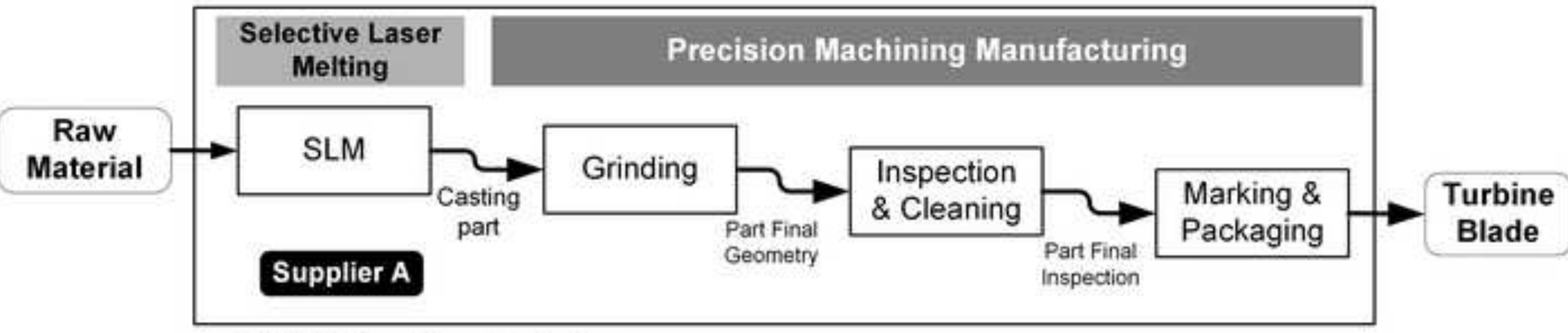

(b) Additive Manufacturing 


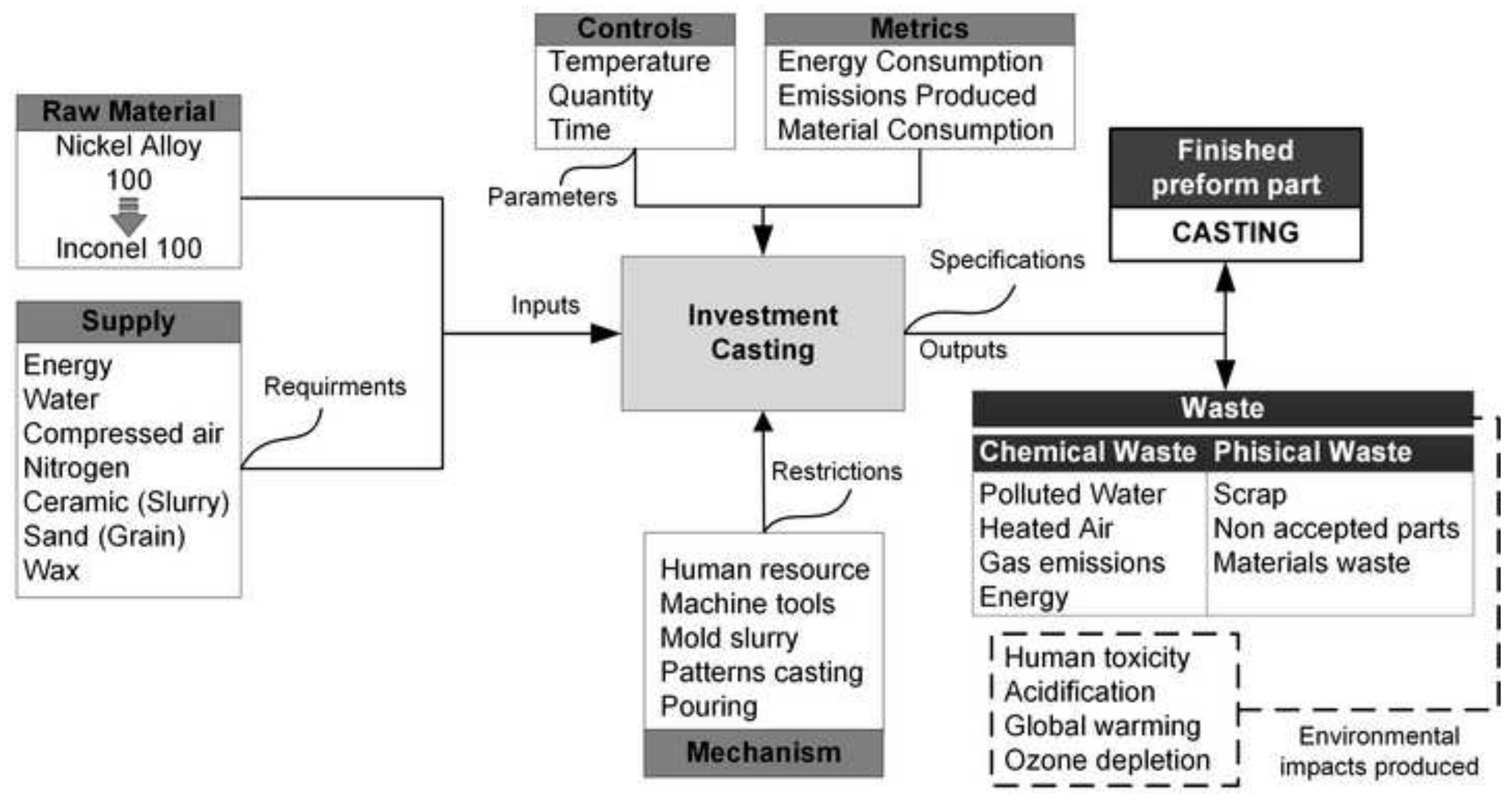




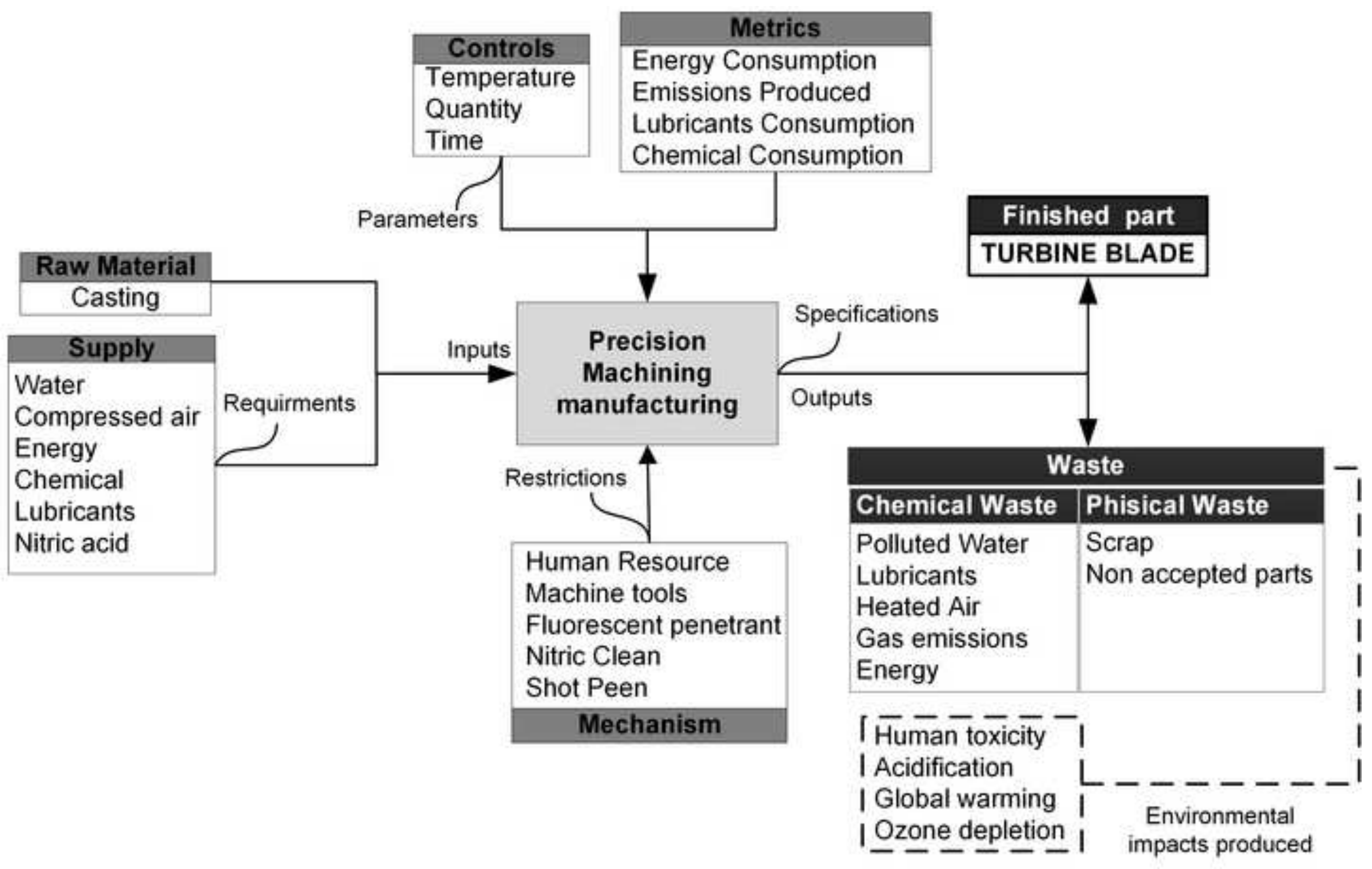




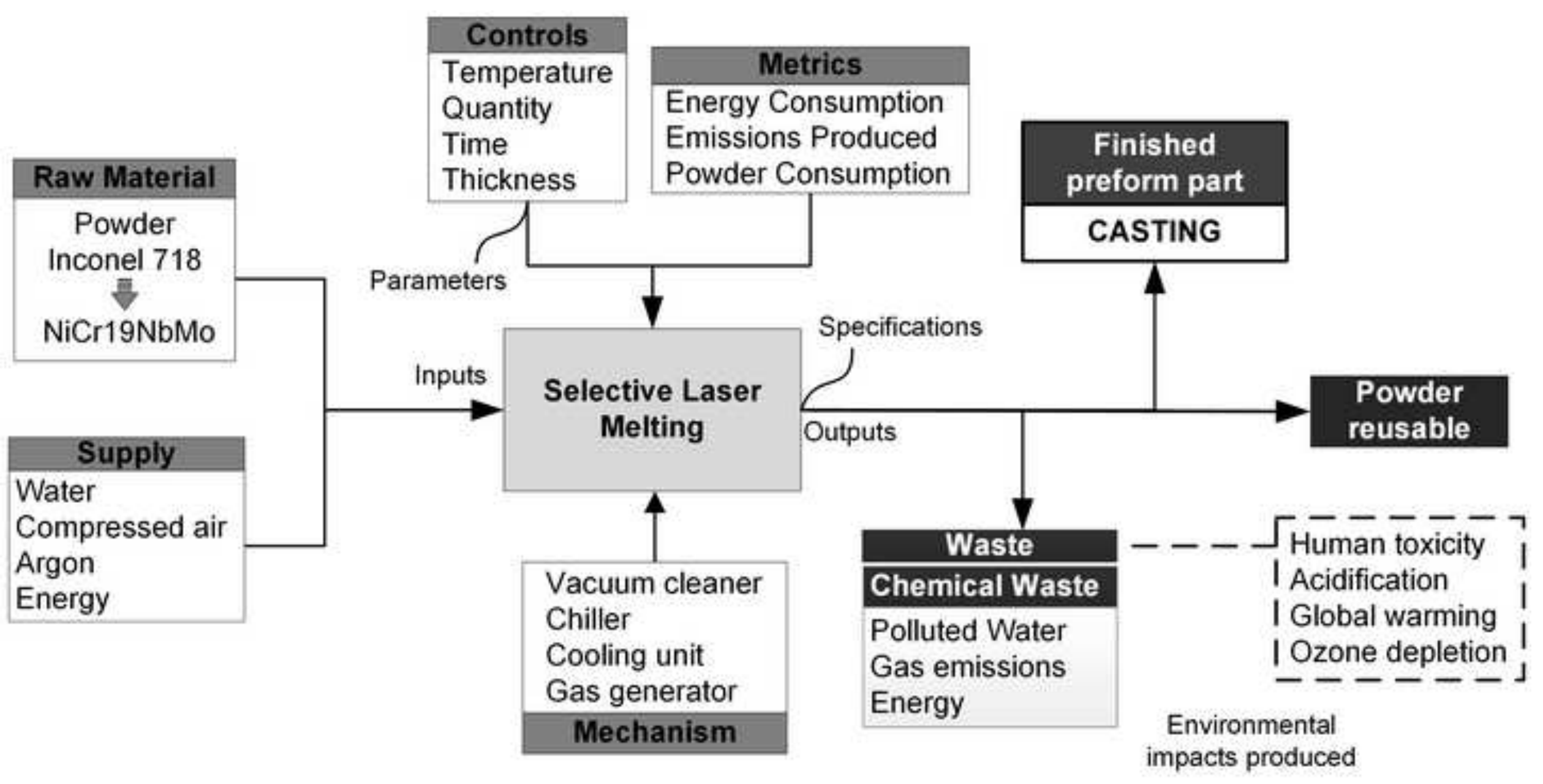


Click here to download high resolution image

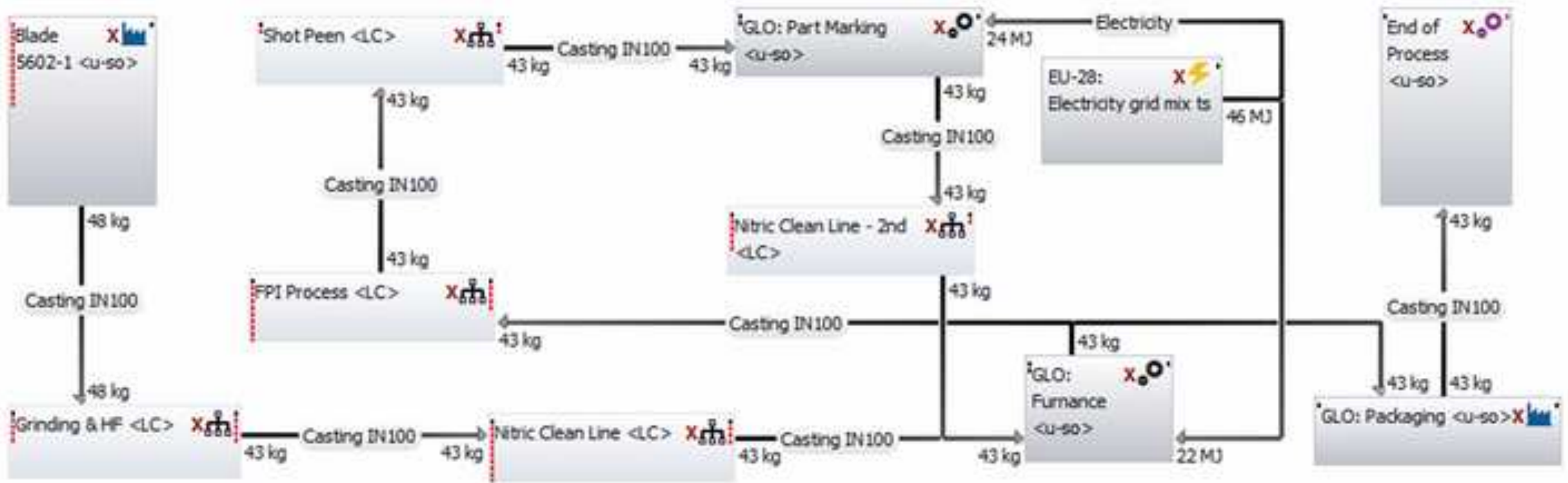


Click here to download high resolution image

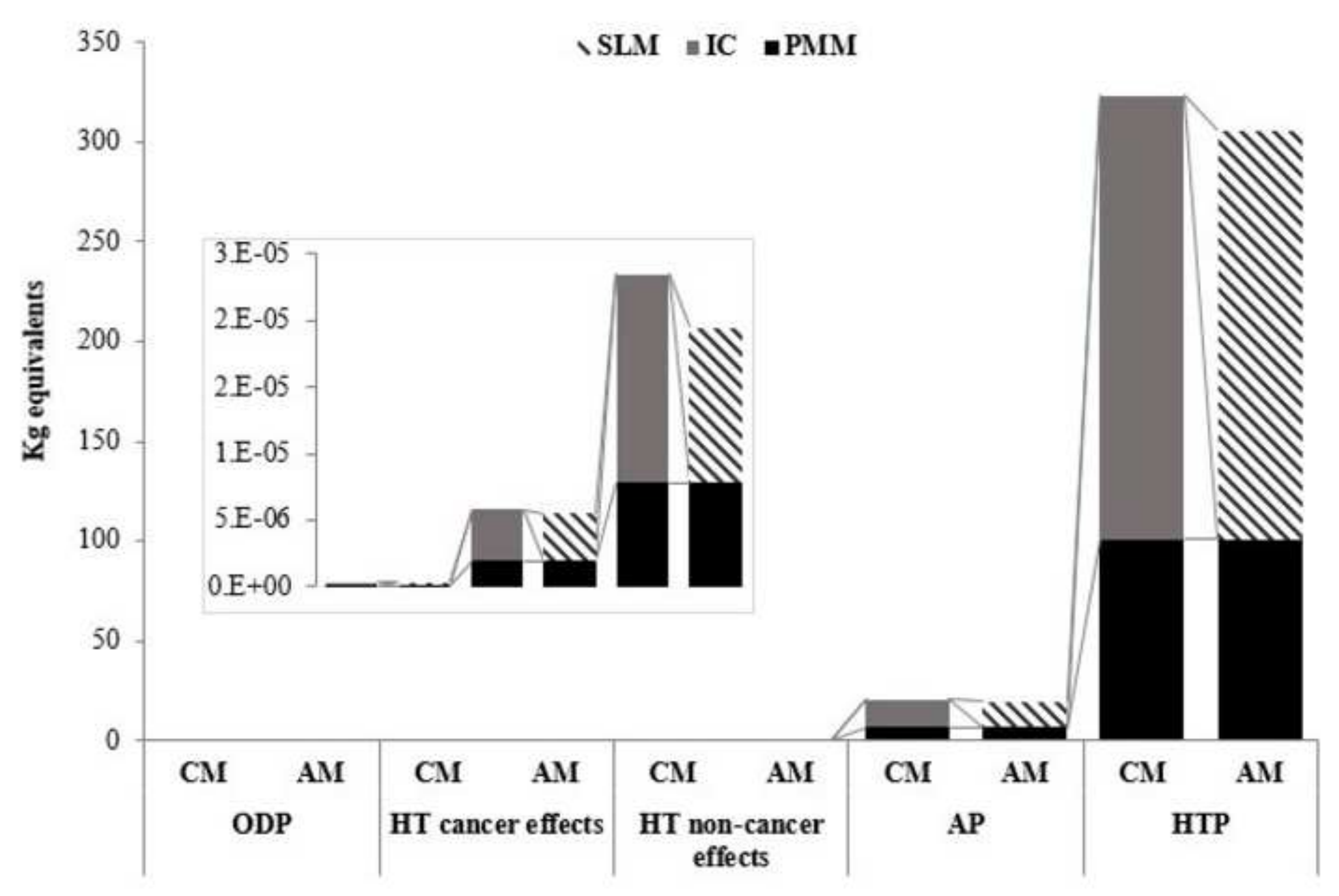


Click here to download high resolution image

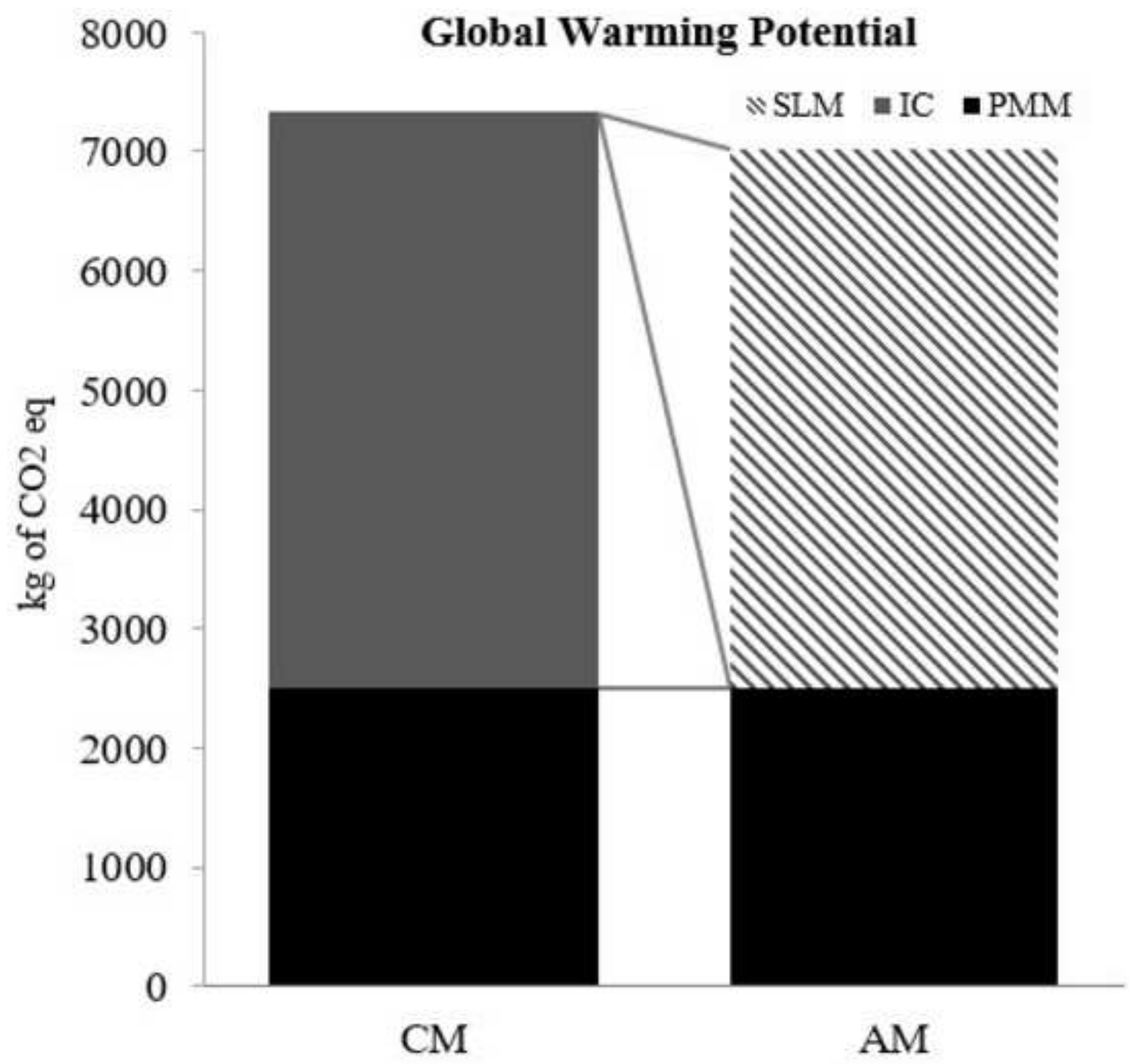


NSLM $\because \mathrm{IC} \quad \mathrm{PMM}$

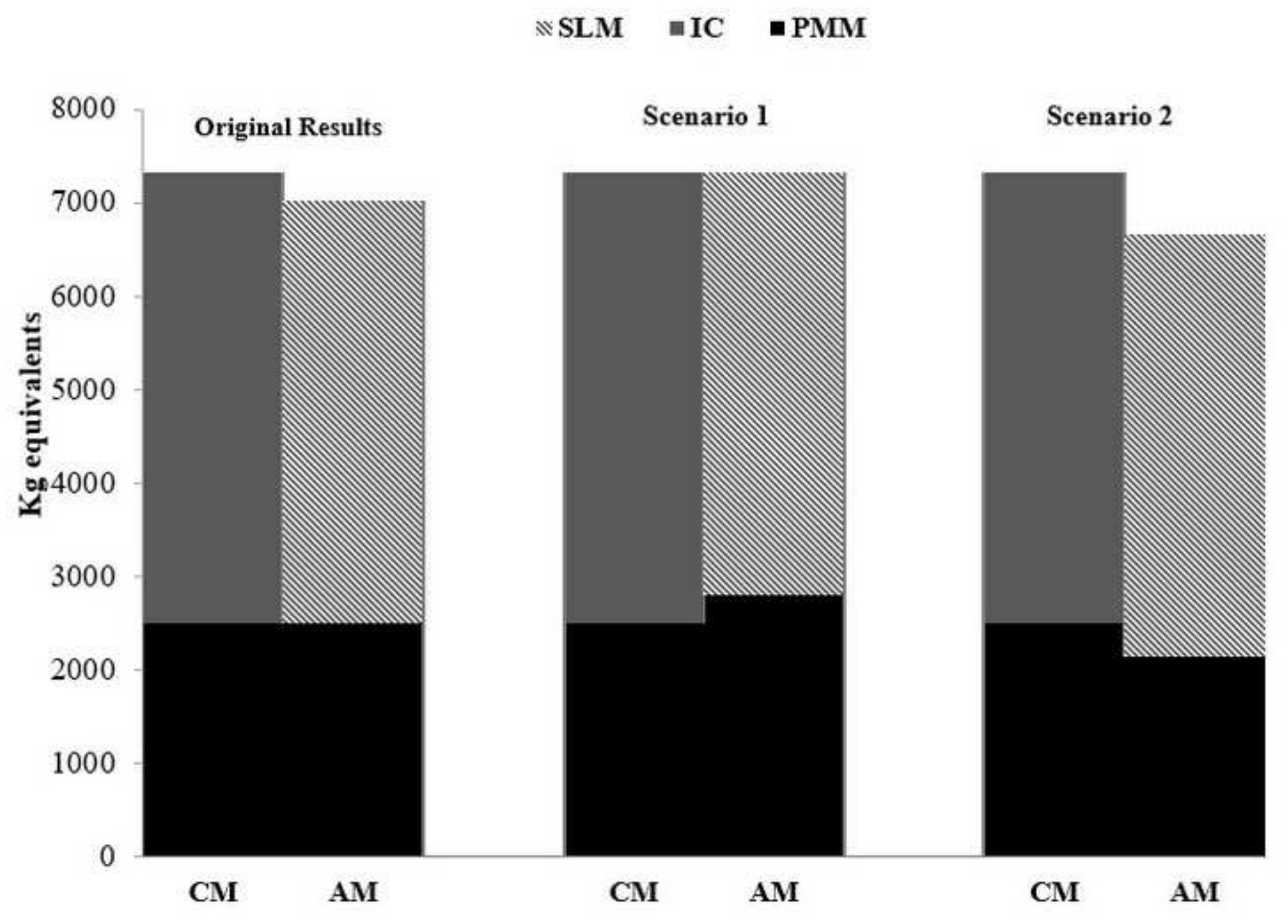


Table 1

A literature review of LCA and its comparison between AM and CNC manufacturing.

\begin{tabular}{|c|c|c|c|c|}
\hline Authors & $\begin{array}{l}\text { AM } \\
\text { Tech }\end{array}$ & Material & $\begin{array}{c}\text { Comparison to } \mathbf{C M} \\
\text { process }\end{array}$ & $\begin{array}{l}\text { Measurement indicators or } \\
\text { methods }\end{array}$ \\
\hline (Ingarao et al., 2018) & SLM & Aluminum alloys & Turning, forming & $\begin{array}{l}\text { ReCiPe characterization } \\
\text { method (Ecopoints) }\end{array}$ \\
\hline (Priarone and Ingarao, 2017) & SLS & $\begin{array}{l}\text { Titanium alloys and } \\
\text { stainless steel }\end{array}$ & Milling & $\begin{array}{l}\text { Energy demand and } \mathrm{CO}_{2} \\
\text { emissions }\end{array}$ \\
\hline (Faludi et al., 2017) & SLM & Aluminum alloys & Milling & $\begin{array}{l}\text { ReCiPe characterization } \\
\text { method (Ecopoints) }\end{array}$ \\
\hline (Kellens et al., 2017) & $\begin{array}{l}\text { SLM } \\
\text { SLS } \\
\end{array}$ & Stainless steel & No & $\begin{array}{l}\text { Powder, gases \& specific } \\
\text { energy consumption }\end{array}$ \\
\hline (Paris et al., 2016) & $\begin{array}{l}\text { SLS } \\
\text { EBM }\end{array}$ & Titanium alloy & Milling & $\begin{array}{l}\text { CML } 2 \text { Baseline } 2000 \text { and } \\
\text { Cumulative Exergy Demand } \\
(\mathrm{CExD})\end{array}$ \\
\hline (Huang et al., 2016) & $\begin{array}{l}\text { SLM } \\
\text { EBM } \\
\text { DMLS }\end{array}$ & $\begin{array}{l}\text { Aluminum, } \\
\text { Titanium, and Nickel } \\
\text { alloys }\end{array}$ & $\begin{array}{l}\text { casting, } \\
\text { machining, } \\
\text { finishing }\end{array}$ & $\begin{array}{l}\text { Primary energy use } \\
\text { reductions and greenhouse } \\
\text { gas emissions }\end{array}$ \\
\hline (Baumers et al., 2011, 2010) & $\begin{array}{l}\text { SLM } \\
\text { EBM } \\
\text { DMLS } \\
\end{array}$ & $\begin{array}{l}\text { Stainless steel } 316 \mathrm{~L} \\
\& \text { Ti6Al4V. }\end{array}$ & No & $\begin{array}{l}\text { Specific energy consumption } \\
\text { and build productivity }\end{array}$ \\
\hline
\end{tabular}


Table 2

Literature review focus on works related with the other classification of metal AM processes.

\begin{tabular}{lllll}
\multicolumn{1}{c}{ Authors } & AM Tech & \multicolumn{1}{c}{ Material } & \multicolumn{1}{c}{$\begin{array}{c}\text { Comparison to CM } \\
\text { process }\end{array}$} & $\begin{array}{c}\text { Measurement indicators or } \\
\text { methods }\end{array}$ \\
\hline (Wilson et al., 2014) & LENS & Nickel alloys & Welding & Energy consumption \\
\hline (Le Bourhis et al., 2014) & DALM & Aluminum & No & $\begin{array}{l}\text { Energy, fluids and material } \\
\text { consumption }\end{array}$ \\
\hline (Serres et al., 2011) & DLAM & Titanium alloys & Machining & Energy consumption \\
\hline (Morrow et al., 2007) & DMD & Tool steel & CNC Milling & Energy consumption \\
\hline
\end{tabular}


Table 3

Description of environmental impact indicators to be measured in the experimental procedure (Adapted from (Europoles GmbH \& Co.KG, n.d.)

\section{Indicator Description}

GWP A measure of how much unit mass of gas contributes to global warming compared to carbon dioxide. A product with a low GWP value causes only low gas emissions contributing to global warming.

AP Refers to the effects of acidifying emissions, therefore, a measure of the environmental impacts of acidification of soils and waters. The higher AP value is higher the risk of acid rain and environmental damage associated with it. The reference compound for calculating is $\mathrm{SO}_{2}$ (sulfur dioxide).

ODP The indicator refers to the thinning of the stratospheric ozone layer because of anthropogenic emissions. This causes a more significant fraction of solar UV-B radiation to reach the earth's surface, with potentially harmful impacts on human health, animal health, terrestrial and aquatic ecosystems.

HTP This impact category covers the impacts on human health of toxic substances present in the environment. The health risks of exposure in the workplace are also sometimes included in LCA. These latter risks are often included in a wider impact category encompassing more than exposure to toxic substances.

HT cancer Human toxicity has a potential to increase human disease per unit mass of a chemical emitted.

effects Comparative toxic unit for human (CTUh), it is the reference quantity of cancer human health effect. 
Table 4

Inventory data to be considered for selected metrics in each manufacturing technology.

\begin{tabular}{lrr} 
Investment Casting & Inputs & Unit \\
Metal bar Inconel 100 & 67.12 & $\mathrm{Kg}$ \\
\hline Ceramic (slurry) & 16.66 & $\mathrm{Kg}$ \\
\hline Sand (grain) & 16.66 & $\mathrm{Kg}$ \\
\hline Wax & 2.4 & $\mathrm{Kg}$ \\
\hline Electricity, production mix & 10853 & $\mathrm{kWh}$ \\
Precision Machining Manufacturing & Inputs & Unit \\
\hline Casting Nickel alloy & 48.06 & $\mathrm{Kg}$ \\
\hline Shot Peen & 4.25 & $\mathrm{Kg}$ \\
\hline Electricity, production mix & 5168 & $\mathrm{kWh}$ \\
\hline Water (desalinated; deionized) & 6889 & $\mathrm{~L}$ \\
\hline Penetrant Liquids (ZR-10B, ZP-4B \& ZL-37) & 27.5 & $\mathrm{~L}$ \\
\hline Cooling oil (CIMTECH 320 \& 610) & 35.39 & $\mathrm{~L}$ \\
\hline Chemical lubricants (Nitric acid, OAKITE \& ECOMATE) & 345 & $\mathrm{~L}$ \\
Selective Laser Melting & Inputs & Unit \\
\hline Powder Inconel 718 & 70.51 & $\mathrm{Kg}$ \\
\hline Electricity, production mix & 10182 & $\mathrm{kWh}$ \\
\hline Water (desalinated; deionized) & 1 & $\mathrm{~L}$ \\
\hline Compressed air & 1 & $\mathrm{Nm} 3$ \\
\hline Argon & 2 & $1 / \mathrm{m}$ \\
\hline
\end{tabular}


Table 5

Output Inventory of general emissions data.

\begin{tabular}{|l|r|r|r|}
\multicolumn{1}{|c|}{ Outputs } & \multicolumn{1}{c|}{ IC } & \multicolumn{1}{c|}{ PMM } & \multicolumn{1}{c|}{ SLM } \\
\hline Emissions to sea water & $1.20 \mathrm{E}+05 \mathrm{~kg} \mathrm{eq}$. & $9.90 \mathrm{E}+03 \mathrm{~kg} \mathrm{eq}$ & $7.39 \mathrm{E}+04 \mathrm{~kg} \mathrm{eq}$ \\
\hline Deposited goods & $3.10 \mathrm{E}+04 \mathrm{~kg} \mathrm{eq}$ & $6.10 \mathrm{E}+04 \mathrm{~kg} \mathrm{eq}$ & $1.96 \mathrm{E}+04 \mathrm{~kg} \mathrm{eq}$ \\
\hline Emissions to air & $1.90 \mathrm{E}+05 \mathrm{~kg} \mathrm{eq}$ & $0.027 \mathrm{~kg} \mathrm{eq}$ & $1.48 \mathrm{E}+05 \mathrm{~kg}$ eq \\
\hline Emissions to fresh water & $3.50 \mathrm{E}+07 \mathrm{~kg} \mathrm{eq}$ & $4.50 \mathrm{E}+02 \mathrm{~kg}$ eq & $2.1 \mathrm{E}+07 \mathrm{~kg}$ eq \\
\hline Emissions to agricultural soil & $0.0053 \mathrm{~kg} \mathrm{eq}$ & $3.80 \mathrm{E}+04 \mathrm{~kg} \mathrm{eq}$ & $0.0034 \mathrm{~kg}$ eq \\
\hline Emissions to industrial soil & $0.078 \mathrm{~kg} \mathrm{eq}$ & $0.0017 \mathrm{~kg} \mathrm{eq}$ & $0.048 \mathrm{~kg}$ eq \\
\hline
\end{tabular}


Table 6

Results of environmental impacts analysis.

\begin{tabular}{lcccccc} 
Indicators & $\mathbf{G W P}$ & $\mathbf{A P}$ & $\mathbf{O D P}$ & $\mathbf{H T P}$ & HT cancer & HT non-cancer \\
Unit (Kg-eq.) & $\mathbf{C O}_{\mathbf{2}}$ & $\mathbf{S O}_{\mathbf{2}}$ & $\mathbf{R 1 1}$ & $\mathbf{D C B}$ & $\mathbf{C T U}_{\mathbf{h}}$ & $\mathbf{C T U}_{\mathbf{h}}$ \\
\hline Investment Casting & 4816.00 & 13.91 & $2.16 \mathrm{E}-07$ & 222.32 & $3.87 \mathrm{E}-06$ & $1.57 \mathrm{E}-05$ \\
\hline Precision Machining & $2,509.28$ & 6.64 & $1.00 \mathrm{E}-07$ & 100.84 & $1.93 \mathrm{E}-06$ & $7.80 \mathrm{E}-06$ \\
\hline Selective Laser Melting & $4,517.92$ & 12.75 & $1.96 \mathrm{E}-07$ & 204.84 & $3.53 \mathrm{E}-06$ & $1.16 \mathrm{E}-05$ \\
\hline \hline Conventional Manufacturing & $7,325.28$ & 20.55 & $3.16 \mathrm{E}-07$ & 323.15 & $5.80 \mathrm{E}-06$ & $2.35 \mathrm{E}-05$ \\
\hline Additive Manufacturing & $7,027.20$ & 19.39 & $2.96 \mathrm{E}-07$ & 305.68 & $5.46 \mathrm{E}-06$ & $1.94 \mathrm{E}-05$ \\
\hline \hline Emission Reduction $(\%)$ & $\mathbf{4}$ & $\mathbf{6}$ & $\mathbf{7}$ & $\mathbf{5}$ & $\mathbf{6}$ & $\mathbf{1 7}$ \\
\hline \hline
\end{tabular}

$\mathrm{CO}_{2}$ : Carbon dioxide; $\mathrm{SO}_{2}$ : Sulphur dioxide; $\mathrm{R} 11$ : Trichlorofluoromethane; DCB: Dichlorobenzene;

$C T U_{h}$ : Comparative toxic unit for human toxicity impacts 
Table 7

Energy consumption of Investment Casting Process.

\begin{tabular}{llrr}
\multicolumn{1}{c}{ Investment Casting Stage } & \multicolumn{1}{c}{ Amount } & Energy (kWh) & $\mathbf{K g ~ C O}_{\mathbf{2}-\mathbf{e q}}$ \\
\hline Raw Material ${ }^{1}$ (Wilson et al., 2014) & $67.12 \mathrm{~kg}$ & 5214.42 & 2314.82 \\
\hline Pattern making tree & 600 parts & 443.93 & 197 \\
\hline Shell-making & 30 Pattern trees & 4842.90 & 2149 \\
\hline Investment Casting & $48.06 \mathrm{~kg}$ & 325.94 & 144.63 \\
\hline Refining and Pouring (Margolis et al., 1999) & $48.06 \mathrm{~kg}$ & 17.46 & 7.70 \\
\hline Cleaning \& Finishing & $48.06 \mathrm{~kg}$ & 8.69 & 3.85 \\
\hline Total & & $\mathbf{1 0 ~ 8 5 3 . 3 4}$ & $\mathbf{4 8 1 6}$ \\
\hline In literature review is called: ${ }^{1}$ Metal in bar stock form. & &
\end{tabular}


Table 8

Energy consumption of Precision Machining Manufacturing process.

\begin{tabular}{llrr}
\multicolumn{1}{c}{ Precision Machining Stage } & Amount & Energy (kWh) & Kg CO $_{\mathbf{2}}$-eq. \\
Grinding & $48.06 \mathrm{~kg}$ & 4817.76 & 2140.49 \\
\hline Nitric Clean & $43.26 \mathrm{~kg}(2 \mathrm{hr})$. & 145.78 & 302.98 \\
\hline FPI Process & $43.26 \mathrm{~kg}$ & 59.31 & 14.27 \\
\hline Shot peen & $43.26 \mathrm{~kg}$ & 22.19 & 9.85 \\
\hline Nitric Clean Second & $43.26 \mathrm{~kg}(0.8 \mathrm{hr})$. & 116.63 & 36.06 \\
\hline Marking \& Packaging & $43.26 \mathrm{~kg}$ & 6.75 & 5.64 \\
\hline Total & & $\mathbf{5 1 6 8 . 4 2}$ & $\mathbf{2 5 0 9 . 2 9}$
\end{tabular}


Table 9

Energy consumption of Selective Laser Melting Manufacturing process.

\begin{tabular}{lrrr}
\multicolumn{1}{c}{ Selective Laser Melting } & Amount & Energy (kWh) & $\mathbf{K g ~ C O}_{\mathbf{2}}$-eq. \\
Raw Material ${ }^{1}$ (Wilson et al., 2014) & $48.06 \mathrm{~kg}$ & 3732.81 & 1656.38 \\
\hline Powder Production (Margolis et al. 1999) & $48.06 \mathrm{~kg}$ & 742.06 & 329.28 \\
\hline SLM Process & 5706.70 & 2532.26 \\
\hline Total & $\mathbf{1 0 ~ 1 8 1 . 5 7}$ & $\mathbf{4 5 1 7 . 9 2}$ \\
\hline In literature review is called: ${ }^{1}$ Metal in bar stock form. & &
\end{tabular}


Table 10

Scenarios data for Sensibility Analysis.

\begin{tabular}{|c|c|c|c|c|c|c|}
\hline \multirow{9}{*}{ 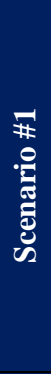 } & Stages & Operations & $\begin{array}{l}\text { Time } \\
\text { (hr) }\end{array}$ & $\mathbf{k W h}$ & $\begin{array}{r}\mathrm{kWh} \\
600 \mathrm{Pz}\end{array}$ & kg CO2 \\
\hline & \multirow{7}{*}{$\begin{array}{c}\text { Grinding and } \\
\mathrm{HF}\end{array}$} & Grind Root Form & 75 & 19.88 & 1490.70 & 662.31 \\
\hline & & Tip/slot & 75 & 19.88 & 1490.70 & 662.31 \\
\hline & & Z Form & 75 & 19.88 & 1490.70 & 662.31 \\
\hline & & Contour Surface & 75 & 19.88 & 1490.70 & 662.31 \\
\hline & & Finishing & 14.3 & 0.60 & 8.53 & 3.8 \\
\hline & & Coordinate Measuring Machine & 50 & 5.27 & 263.46 & 117 \\
\hline & & Hand Finish & 75 & 0.98 & 73.66 & 32.7 \\
\hline & \multicolumn{2}{|r|}{ Total } & 439 & 86.35 & 6308.45 & 2802.80 \\
\hline \multirow{7}{*}{ 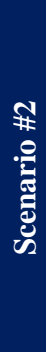 } & \multirow{6}{*}{$\begin{array}{c}\text { Grinding and } \\
\mathrm{HF}\end{array}$} & Grind Root Form & 75 & 19.88 & 1490.70 & 662.31 \\
\hline & & Tip/slot & 75 & 19.88 & 1490.70 & 662.31 \\
\hline & & Z Form & 75 & 19.88 & 1490.70 & 662.31 \\
\hline & & Finishing & 50 & 0.60 & 29.85 & 13.26 \\
\hline & & Coordinate Measuring Machine & 50 & 5.27 & 263.46 & 117 \\
\hline & & Hand Finish & 75 & 0.98 & 73.66 & 32.7 \\
\hline & & Total & 400 & 66.48 & 4839.07 & 2149.96 \\
\hline
\end{tabular}


Appendix Table 1

Quantitative Data Collection of electricity in Investment Casting.

\begin{tabular}{|c|c|c|c|}
\hline Stages & Machines & $\mathbf{k W h}$ & kWh 600pz \\
\hline Raw Material & Fabrication of raw metal & & 5214.42 \\
\hline \multirow{4}{*}{ Patterns making tree } & Wax model design & N.C & \multirow{4}{*}{443.93} \\
\hline & Wax mold fabrication & 4.93 & \\
\hline & Wax injection & 4.93 & \\
\hline & Pattern assembly & 4.93 & \\
\hline \multirow{2}{*}{ Shell-making } & Refractory slurry and grain & 43.05 & \multirow{2}{*}{4842.89} \\
\hline & Dry & 118.38 & \\
\hline Investment Casting & Investment Casting & & 325.94 \\
\hline Refining and Pouring & Pouring & & 17.46 \\
\hline \multirow{4}{*}{ Cleaning \& Finishing } & Knock out / shakeout & 1.25 & \multirow{4}{*}{8.69} \\
\hline & Cleaning rotatory system & 1.25 & \\
\hline & Cut off & 2.27 & \\
\hline & Grinding & 3.92 & \\
\hline
\end{tabular}


Appendix Table 2

Quantitative Data Collection of electricity in Precision Machining Manufacturing.

\begin{tabular}{|c|c|c|c|}
\hline Stages & Operations & $\mathbf{k W h}$ & kWh 600Pz \\
\hline \multirow{6}{*}{ Grinding and $\mathrm{HF}$} & Grind Root Form & 19.876 & 1490.7 \\
\hline & Tip/slot & 19.876 & 1490.7 \\
\hline & Z Form & 19.876 & 1490.7 \\
\hline & Finishing & 0.597 & 8.53 \\
\hline & Coordinate Measuring Machine & 5.269 & 263.46 \\
\hline & Hand Finish & 0.982 & 73.66 \\
\hline \multirow{5}{*}{ Nitric Clean Line } & Furnance & \multirow{5}{*}{36.45} & \multirow{5}{*}{145.78} \\
\hline & Pumping system & & \\
\hline & Scrubber VIRON & & \\
\hline & Feeding boards & & \\
\hline & Tanks (10 tanks) & & \\
\hline \multirow{7}{*}{ FPI Process } & Penetrating impregnation & \multirow{7}{*}{14.83} & \multirow{7}{*}{59.31} \\
\hline & Prewash & & \\
\hline & Emulsifying tank & & \\
\hline & Postwash & & \\
\hline & Resistance drying furnace & & \\
\hline & Revealed cabin & & \\
\hline & FPI Inspection & & \\
\hline \multirow{4}{*}{ Final Operation } & Shot Peen & 4.44 & 22.19 \\
\hline & Part Marking & 0.23 & 6.75 \\
\hline & Finish Visual Inspection & 0 & 0 \\
\hline & Nitric Clean Second Line & 14.58 & 116.63 \\
\hline
\end{tabular}


Appendix Table 3

Appendix Table 3

Quantitative Data Collection of electricity in Selective Laser Melting.

\begin{tabular}{|c|c|c|}
\hline Machine & $\mathbf{k W h}$ & $\mathbf{k W h} \mathbf{6 0 0} \mathbf{p z}$ \\
\hline Feeding boards & 28.141 & 842.43 \\
\hline Cooling Unit & 1.552 & 465.58 \\
\hline Powder Sieving Station & 0.030 & 9.07 \\
\hline Inert Gas-Generator & 0.515 & 154.56 \\
\hline EdNiCon Workbench & 0.016 & 4.89 \\
\hline Metal in bar stock form & & 3732.81 \\
\hline Powder Production & & 742.06 \\
\hline
\end{tabular}


Appendix Table 4

Quantitative Data Collection of materials in Turbine Blade Manufacturing.

\begin{tabular}{|c|c|c|}
\hline Area & Operation & Material* (kg.) \\
\hline \multicolumn{3}{|c|}{ *Raw Material } \\
\hline $\mathrm{IC}$ & Metal in bar & 67.12 \\
\hline PMM & Casting & 48.06 \\
\hline SLM & Powder metal & 70.51 \\
\hline \multicolumn{3}{|c|}{ *Refractory Slurry } \\
\hline \multirow[t]{2}{*}{ Shell Making } & Ceramic & 16.66 \\
\hline & Slurry & 16.66 \\
\hline \multicolumn{3}{|c|}{$* \mathrm{Wax}$} \\
\hline Pattern making tree & Wax injection & 2.40 \\
\hline \multicolumn{3}{|c|}{ *Casting Weight } \\
\hline \multirow[t]{5}{*}{ Grinding and $\mathrm{HF}$} & Grind Root Form & 48.06 \\
\hline & Grind wire & 44.34 \\
\hline & Grind Z Form & 43.68 \\
\hline & HASS & 43.32 \\
\hline & Finished Part & 43.26 \\
\hline \multicolumn{3}{|c|}{ *Cast Steel Shot } \\
\hline Shot Peen & Shot Peen & 4.25 \\
\hline
\end{tabular}




\section{Appendix Table 5}

Quantitative Data Collection of fluids in Precision Machining Manufacturing.

\begin{tabular}{|c|c|c|c|}
\hline Area & Operation & Water (L) & Fluids* (L) \\
\hline \multicolumn{4}{|c|}{ *Lubricants } \\
\hline \multirow[t]{6}{*}{ Grinding and $\mathrm{HF}$} & Grind Root Form & 250 & 11.88 \\
\hline & Tip/slot & 187.5 & 7.50 \\
\hline & Z Form & 206.25 & 14.09 \\
\hline & Finishing & 20 & 2 \\
\hline & $\begin{array}{l}\text { Coordinate Measuring } \\
\text { Machine }\end{array}$ & 0 & 0 \\
\hline & Hand Finish & 0 & 0 \\
\hline \multicolumn{4}{|c|}{ *Chemicals } \\
\hline \multirow[t]{10}{*}{ Nitric Clean Line } & Tank \#101 & 577.51 & 115 \\
\hline & Tank \#102 & 577.51 & 0 \\
\hline & Tank \#103 & 577.51 & 0 \\
\hline & Tank \#104 & 577.51 & 115 \\
\hline & Tank \#105 & 577.51 & 0 \\
\hline & Tank \#106 & 577.51 & 0 \\
\hline & Tank \#107 & 577.51 & 115 \\
\hline & Tank \#108 & 577.51 & 0 \\
\hline & Tank \#109 & 577.51 & 0 \\
\hline & Tank \#110 & 577.51 & 0 \\
\hline \multicolumn{4}{|c|}{ *Penetrant Liquids } \\
\hline \multirow[t]{7}{*}{ FPI Process } & Penetrating impregnation & 0 & 15 \\
\hline & Prewash & 150 & 0 \\
\hline & Emulsifying tank & 150 & 10 \\
\hline & Postwash & 150 & 0 \\
\hline & Resistance drying & 0 & 0 \\
\hline & Revealed cabin & 0 & 2.5 \\
\hline & FPI Inspection & 0 & 0 \\
\hline
\end{tabular}

